\title{
Predictive Maintenance Applied to Three Phase Induction Motors
}

\author{
Fatma Zohra DEKHANDJI, Salah Eddine HALLEDJ and Oussama ZABOUB \\ Smart Grid Team, Laboratory of Signals and Systems, Institute of Electrical and Electronic \\ Engineering, University M'hamed Bougara of Boumerdes \\ Boulevard de l'indépendance, 35000, Boumerdes, Algeria \\ 'fzdekhandji@univ-boumerdes.dz
}

\begin{abstract}
Induction machines are widely used in industry. The operating conditions may sometimes lead the machine into different fault situations. The machine should be shut down when a fault is experienced to avoid complete process failure and for the safety of the workers. The predictive maintenance consists of scheduling maintenance activities only when a functional failure is detected. The advantages of predictive maintenance are accepted in many industries because of its efficiency in fault detection during early stages and thus reducing unscheduled down time. It increases productivity, improves quality and provides the feeling of safety and reliability to staff. The main types of external faults experienced by these motors are over loading; single phasing, unbalanced supply voltage, phase reversal, ground fault, under voltage and over voltage. MATLAB/SIMULINK simulation is used in this work for the detection and analysis of the faults on induction motor.
\end{abstract}

Keywords: Induction machines, Preventive maintenance, Reliability, faults.

\section{INTRODUCTION}

Induction motors are widely used in industrial applications. Despite their reliability, failures will inevitably happen. Industries have implemented maintenance programs based on diverse procedures. Some include resistance, vibration and thermography while others integrate techniques such as Motor Current Signature Analysis to enhance the results. Hence, a blend of techniques may be needed when evaluating the motor's health [1-6].

The goal of a predictive maintenance program is to identify an unsatisfactory condition well before it results in motor failure. Unplanned, catastrophic motor failures result in costly downtime and are generally quite more expensive and difficult to repair. In addition, replacement motors are not always readily available from the manufacturers, and the storage of spare motors as replacements is costly and not always practical [4].

Cite this article as:

Fatma Zohra DEKHANDJI, Salah Eddine HALLEDJ and Oussama ZABOUB, "Predictive Maintenance Applied to Three Phase Induction Motors", Algerian Journal of Signals and Systems, Vol. 4, Issue 2, December 2019.pp: 7188.
Many predictive techniques are applied to these motors to reduce the number of unplanned outage. The most common techniques applied to fault detection in induction motors are: vibration analysis, acoustical analysis, speed oscillations, partial discharges, circuit analysis etc.[3].

In this increasing demand for prediction technology, a specific technique referred as Electrical Signature Analysis (ESA) is calling more and more attention of industries. Considering this context, this chapter intends to disseminate important concepts to guide companies that have their own predictive group or want to hire consultants or specialized service to obtain good results through general predictive maintenance practices and, especially through electrical signature analysis $[4,6]$.

Figure 1 presents the comparative between vibration analysis and ESA (considering Motor Current Signature Analysis (MCSA), Extended Park's Vector Approach (EPVA) and Instantaneous Power Signature Analysis (IPSA)), showing which technique is more recommended to a specific kind of problem in a determined part of the rotating drive train. One can say that those techniques are complementary and may be all used [6]. 


\section{BASICS OF INDUCTION MOTORS}

The induction motor is the most popular type of ac motor because of its simplicity and ease of operation, an induction motor does not have a separate field circuit; instead, it depends on transformer action to induce voltages and currents in its field circuit.

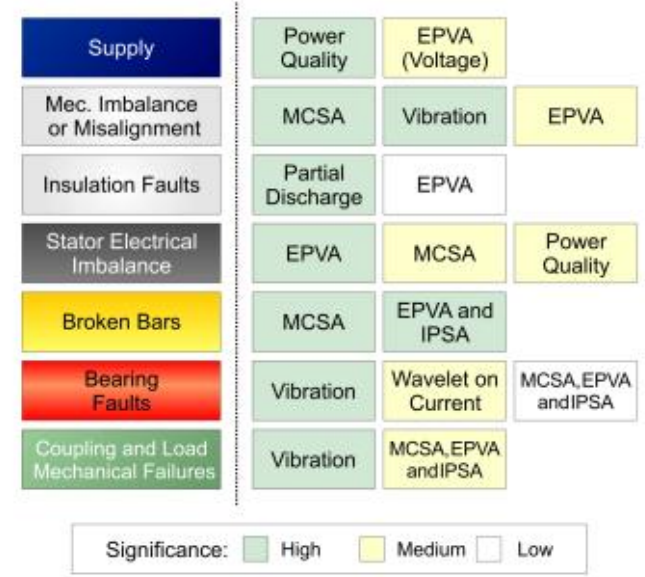

Fig.1 Comparison of predictive maintenance techniques [6]

In fact, an induction motor is basically a rotating transformer. Its equivalent circuit is similar to that of a transformer, except for the effects of varying speed. Cage rotors consist of a series of parallel bars all around the rotor, shorted together at each end [7]. Dynamic model of the SCIM

Dynamic model includes three preferred speeds or reference frames as follows: they are (i) the stationary reference frame when the dq axes do not rotate. (ii) the rotor reference frame when the dq axes rotate at rotor speed. (iii) Synchronously rotating reference frame when the dq axes rotate at synchronous speed. Using any of the three reference frame, the transient nature of the machine can be analyzed. Here, synchronous reference frame is used since the start and rotor voltages are balanced. The induction machine is highly symmetrical. During the starting as well as during the other transient operations the induction motors draw large current which results in voltage drips, oscillatory torques and even generate the harmonics in the power systems. The dq axis model is more reliable and accurate to investigate such of these problems. The dynamic model is derived by using two-phase motor in direct and quadrature. This approach is useful because of the conceptual simplicity obtained with two set of windings one is on the stator and other is on the rotor [9].

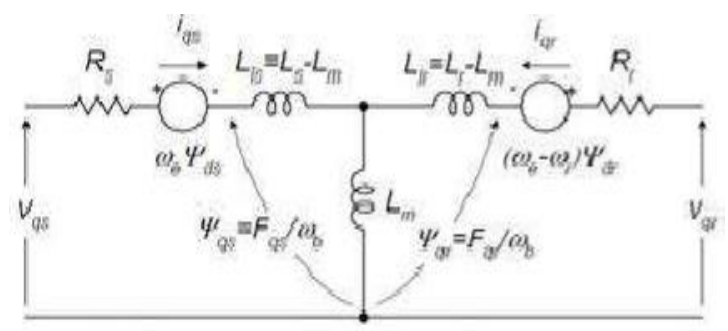

(a)



Fig. 2 a-Dynamic $d$ - $q$ equivalent circuits of machine (a) q-axes, (b) $d$-axes circuit

Flux linkage as variables can be used in dynamic equations of the induction motor in any reference frame. This involves the reduction of a number of variables in the dynamic equations. If the voltages and currents are discontinuous then also the flux linkages are continuous. The flux linkages of the stator and rotor can be described as:

$$
\begin{gathered}
F_{q s}=L_{s} i_{q s}+L_{m} i_{q r} \\
F_{d s}=L_{s} i_{d s}+L_{m} i_{d r} \\
F_{q r}=L_{r} i_{q r}+L_{m} i_{q s} \\
F_{q s}=L_{r} i_{d r}+L_{m} i_{d s}
\end{gathered}
$$

When we expand the equation shown in figure, we get:

$$
\begin{aligned}
& V_{q s}=R_{s} i_{q s}+L_{s} \frac{d}{d t} i_{q r}+\omega_{e} L_{s} i_{d s}+L_{m} \frac{d}{d t} i_{q r} \\
& +\omega_{e} L_{m} i_{d r}(5 . a) \\
& V_{d s}=R_{s} i_{d s}+L_{s} \frac{d}{d t} i_{d s}+\omega_{e} L_{s} i_{q s}+L_{m} \frac{d}{d t} i_{d r} \\
& -\omega_{e} L_{m} i_{q r}(5 . b) \\
& V_{q r}=R_{r} i_{q s}+L_{r} \frac{d}{d t} i_{q r}+\left(\omega_{e}-\omega_{r}\right) L_{m} i_{d s} \\
& +L_{m} \frac{d}{d t} i_{q s}+\left(\omega_{e}\right. \\
& \left.-\omega_{r}\right) L_{m} i_{d r}(5 . c) \\
& V_{d r}=R_{r} i_{d r}+L_{r} \frac{d}{d t} i_{d r}-\left(\omega_{e}-\omega_{r}\right) L_{m} i_{q s} \\
& +L_{m} \frac{d}{d t} i_{d s}+\left(\omega_{e}\right. \\
& \left.-\omega_{r}\right) L_{r} i_{q r} \quad(5 . d)
\end{aligned}
$$

From equations we find out the derivative of $i_{d r}, i_{d s}, i_{\text {qr }} i_{q s}$ and modeling is performed. Finally, the value of stator current is the resultant of ids and iqs :

$$
I s=\frac{2}{3} \sqrt{i_{d s}^{2}+i_{q s}^{2}}
$$

The electromagnetic torque in synchronous frame: 


$$
T=\frac{3 P L m}{4}[\text { IdsIqs }- \text { IqsIdr }]
$$

The electro-mechanical torque :

$$
T_{e}=T_{L}+\frac{2}{P} j \frac{d \omega_{r}}{d t}
$$

\section{A. Loss and the Power-Flow Diagram}

The relationship between the input electric power and the output mechanical power of this motor is shown in the power-flow diagram in Figure 3.

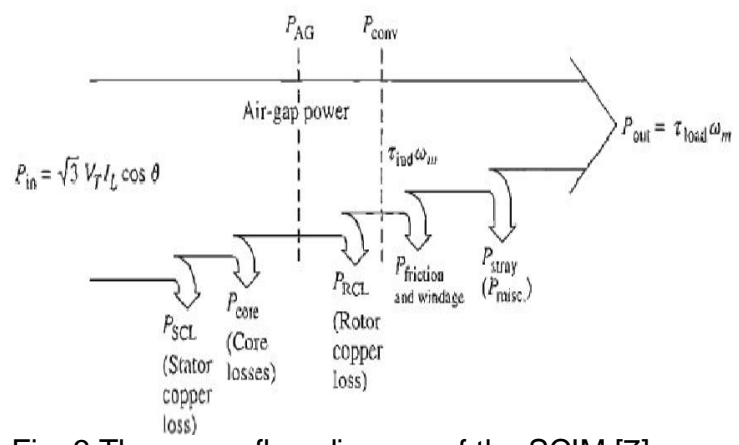

Fig. 3 The power flow diagram of the SCIM [7]

The input power to an induction motor is in the form of three-phase electric voltages and currents. The first losses encountered in the machine are $\mathrm{Rl}^{2}$ losses in the stator windings (the stator copper loss $\mathrm{P}_{\mathrm{SCL}}$ ). Then some amount of power is lost as hysteresis and eddy currents in the stator ( $\left.\mathrm{P}_{\text {CORE }}\right)$. The power remaining at this point is transferred to the rotor of the machine across the air gap between the stator and rotor. This power is called the air-gap power $P_{A G}$ of the machine. After the power is transferred to the rotor, some of it is lost as $R i^{2}$ losses (the rotor copper loss $\mathrm{P}_{\mathrm{RCL}}$ ), and the rest is converted from electrical to mechanical form $P_{\text {conj. }}$. Finally, friction and windage losses $\mathrm{P}_{\mathrm{F} \& \mathrm{~W}}$ and stray losses $P_{\text {MISC }}$ are subtracted. The remaining power is the output of the motor Pout [7].

The core losses of an induction motor come partially from the stator circuit and partially from the rotor circuit. The rotor core losses are very tiny compared to the stator core losses. Since the largest fraction of the core losses comes from the stator circuit, all the core losses are lumped together at that point on the diagram. These losses are represented in the induction motor equivalent circuit by the resistor Rc. The higher the speed of an induction motor; the higher its friction, windage, and stray losses. On the other hand; the higher the speed of the motor (up to $n_{S Y N C}$ ), the lower its core losses [7-8].

\section{B. Induction Motor Design Classes:}

The NEMA standards mainly specify four design types for $A C$ induction motors -Design $A, B, C$ and $D$. These classes, their starting torque and, applications are shown in table 1 and their typical torque-speed curves are shown in figure 4 [9].

Table 1 the induction motor design classes

\begin{tabular}{|c|c|c|c|}
\hline $\begin{array}{c}\text { Design } \\
\text { class }\end{array}$ & $\begin{array}{c}\text { Starting } \\
\text { torque }\end{array}$ & Slip & applications \\
\hline Class A & $\begin{array}{c}150- \\
170 \% \text { of } \\
\text { the rated }\end{array}$ & $<5 \%$ & $\begin{array}{c}\text { Powering of injection } \\
\text { moulding machines }\end{array}$ \\
\hline Class B & $\begin{array}{c}\text { Normal } \\
\text { starting }\end{array}$ & $<5 \%$ & Pumps, fans \\
\hline Class C & $\begin{array}{c}200 \% \text { of } \\
\text { rated }\end{array}$ & $<5 \%$ & $\begin{array}{c}\text { Crushers, stirring } \\
\text { machine,compressors }\end{array}$ \\
\hline Class D & $\begin{array}{c}\text { Very high } \\
\text { starting }\end{array}$ & $\begin{array}{c}5- \\
13 \%\end{array}$ & $\begin{array}{c}\text { Oil-well pumping } \\
\text { cranes, } \\
\text { elevators,shears }\end{array}$ \\
\hline
\end{tabular}

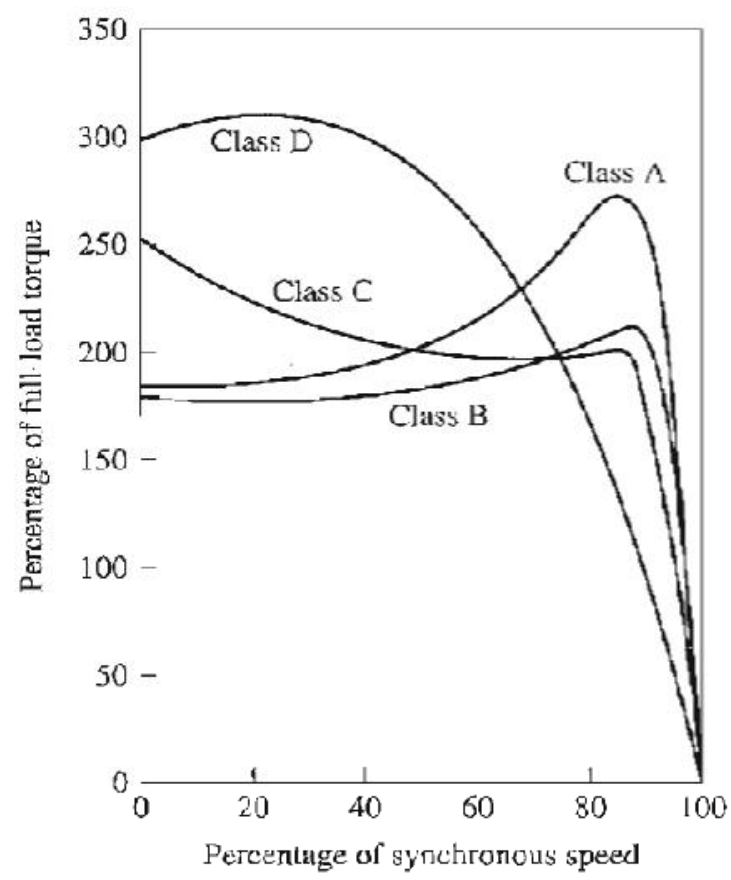

Fig. 4 Torque vs. speed characteristics of different classes of the SCIM

\section{H. Induction motor faults}

Broken Rotor Bar Fault: It is a mechanical fault. If one or more of the rotor bars is partially cracked or completely broken, then the motor is said to have broken bar fault shows rotor and parts of broken rotor bar. It has been observed that in squirrel-cage induction motor rotor asymmetry occurs mainly due to manufacturing defect, such as during the brazing process non uniform metallurgical stresses may occur in cage assembly which led to failure during rotation 
of the rotor. Also heavy end rings of rotor result in large centrifugal forces which may cause extra stresses on the rotor bars. Because of any of the reasons rotor bar may get damage which results in asymmetrical distribution of rotor currents. Now if one of the bars breaks, the side bars will carry higher currents for which larger thermal and mechanical stresses may happen on these side bars. If the rotor continues to rotate in this condition damage may spread, leading to fracture of multiple bars of the rotor. This cracking may occur the joints of bars and end rings. Moreover, possibilities of crack increase if motor start-up time is long and also if motor is subject to frequent starts and stops [10].

The main causes of rotor broken bar of an induction motor are: manufacturing defects, thermal stresses, mechanical stress caused by bearing faults, frequent starts of the motor at rated voltage, fatigue of metal of the rotor bar. Cracked or broken bar fault produces a series of sideband frequencies, in the stator current signature given by $\left(F_{\text {brb }}-\right.$ $f(1 \pm 2 k s)$ ) where $f$ is the supply frequency, $s$ is the slip, and $k$ is an integer. This is called ripple effect, which explains that the lower side band at $f(1-2 s)$ is the strongest which will cause ripples of torque and speed at a frequency of 2 sf and this in turn will induce an upper side band at $f(1+2 s)$ and this effect will continue to create the above series of sidebands. Magnitude of this lower sideband $f(1-2 s)$ over the fundamental can be used as an indicator of rotor broken bar fault .

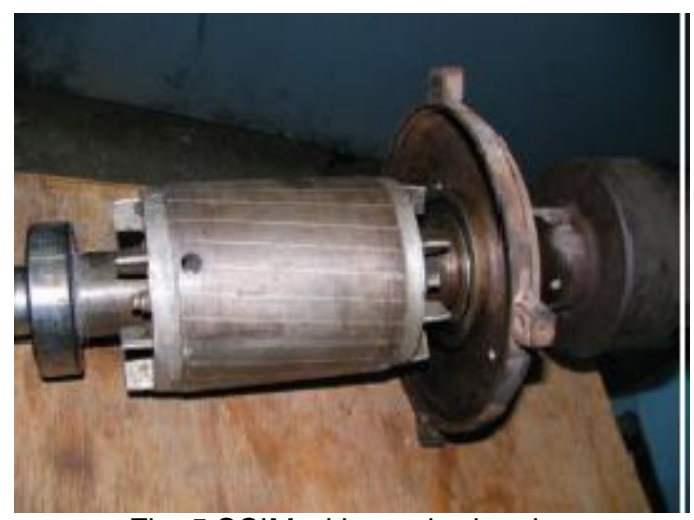

Fig. 5 SCIM with one broken bar

Bearing Fault: It is a mechanical fault .Two sets of bearings are placed at both the ends of the rotor of an induction motor to support the rotating shaft. They held the rotor in place and help it to rotate freely by decreasing the frictions. Each bearing consists of an inner and an outer ring called races and a set of rolling elements called balls in between these two races. Any physical damage of the inner race or in the outer race or on the surface of the balls is termed as bearing fault. In terms of induction motor failure, bearing is the weakest component of an induction motor. It is the largest cause of fault in induction motor the following is a list of bearing fault causes and failures [11].

- Excessive loads, tight fits, and excessive temperature rise: all of these can anneal the two races and ball materials. They can also degrade, even destroy, the lubricant.

- Corrosion: this results if bearings are exposed to corrosive fluids (acids, etc.) or corrosive atmosphere. If lubricants deteriorate or the bearings are handled carelessly during installation, then also corrosion of bearings may take place.

- Lubricant failure: for restricted flow of lubricant or excessive temperature this takes place. It degrades the property of the lubricant for which excessive wear of balls and races takes place which results in overheating. If bearing temperature gets too high, grease (the lubricant) melts and runs out of bearing.

- Misalignment of bearings: for this, wear in the surfaces of balls and races takes place which results in rise in temperature of the bearings. It is observed that for any of the bearing failures, normally friction increases which causes rise in temperature of the bearings and increase in vibration of the concerned machine.

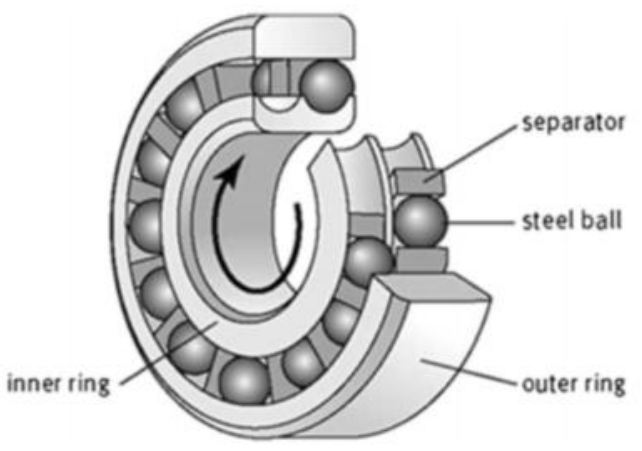

Fig. 6 The bearing of the SCIM

Stator Fault: Two main classes of stator winding failures are (i) open phase failure and (ii) short circuit of few turns in a phase 
winding. The former allows the machines to operate with reduced torque while the latter leads to the catastrophic fault in a short time. When there is an open circuit, a strong electrical asymmetry will be there for which negative sequence current will be obtained. Continuous monitoring of the negative sequence of stator current is usually done in case of rotor open circuit fault. A short circuit is recognized as one of the most difficult failures to detect. Inter-turn to turn short circuit in stator windings constitutes a category of fault that is the most common in induction motors. Typically, short circuit in stator winding occurs between turns of one phase, or between turns of two phases, or between turns of all phases. Moreover, short circuits between winding conductors and the stator core also occur [12].

Overloading: It is an electrical fault. Overload fault occurs when the mechanical torque exceeds the threshold point by applying mechanical load to the motor greater than full load rating. Overloading causes increase in phase currents, over heating the machine.

Unbalanced supply voltage: It is an electrical fault. There are many causes of unbalance supply voltages such as unbalance loading, open delta transformers and unequal tap setting. This condition leads to reduction in motor efficiency, raises the motor temperature and excessive unbalanced full load).

Phase reversal: It is an electrical fault. Phase reversal occurs when any of the two phases are reversed from the normal sequence, which leads the motor to rotate in the opposite direction. When the motor starts to rotate in the opposite direction, it can cause intensive damage.

Under voltage: It is an electrical fault .Under voltage fault is reducing the supply voltage on the three phases by specific percentage, which makes the motor from attaining rated speed in specified time, increases the current and overheats the machine.

Over Voltage: It is an electrical fault. Over voltage occur if the three phase voltages are greater than rated voltage. The effect of this fault is increasing current flow which leads unacceptable stress on the motor insulation due to high heat dissipation. Conventional protection systems use the over voltage relays to protection the motor during this condition.

\section{PREDICTIVE MAINTENANCE}

The maintenance philosophies can usually be divided into three different categories: Corrective or run to failure maintenance, Preventive or time-based maintenance, and Predictive or condition-based maintenance. This philosophy consists of scheduling maintenance activities only when a functional failure is detected. Mechanical and operational conditions are periodically monitored, and when unhealthy trends are detected, the troublesome parts in the machine are identified and scheduled for maintenance.

\section{A. Principles of predictive maintenance}

Predictive maintenance is basically a condition-driven preventive maintenance. Industrial or in-plant average life statistics are not used to schedule maintenance activities in this case. Predictive maintenance monitors mechanical condition, equipment efficiency and other parameters and attempts to derive the approximate time of a functional failure.

Predictive maintenance uses various techniques to assess the equipment condition. Defects that occur in a machine always exhibit a symptom in the form of vibration or some other parameter. However, this may or may not be easily detected on machinery systems with human perceptions. It is here that predictive maintenance techniques come to assistance. These techniques detect symptoms of the defects that have occurred in machines and assist in diagnosing the exact defects that have occurred. In many cases, it is also possible to estimate the severity of the defects.

\section{$B$. Predictive maintenance techniques}

There are numerous predictive maintenance techniques, including:

- Vibration monitoring.

- MCSA

- Thermography.

- Ultrasound

\section{B.1. Vibration analysis:}

Vibration analysis is used to determine the operating and mechanical condition of equipment. A major advantage is that vibration analysis can identify developing problems before they become too serious and cause unscheduled downtime. This can be achieved by conducting regular monitoring of machine vibrations either on continuous 
basis or at scheduled intervals. Regular vibration monitoring can detect deteriorating or defective bearings, mechanical looseness and worn or broken gears. Vibration analysis can also detect misalignment and unbalance before these conditions result in bearing or shaft deterioration. Trending vibration levels can identify poor maintenance practices, such as improper bearing installation and replacement, inaccurate shaft alignment or imprecise rotor balancing.

All rotating machines produce vibrations that are a function of the machine dynamics, such as the alignment and balance of the rotating parts. Measuring the amplitude of vibration at certain frequencies can provide valuable information about the accuracy of shaft alignment and balance, the condition of bearings or gears, and the effect on the machine due to resonance from the housings, piping and other structures.

Vibration measurement is an effective, nonintrusive method to monitor machine condition during start-ups, shutdowns and normal operation. Vibration analysis is used primarily on rotating equipment such as steam and gas turbines, pumps, motors, compressors, paper machines, rolling mills, machine tools and gearboxes.

Recent advances in technology allow a limited analysis of reciprocating equipment such as large diesel engines and reciprocating compressors. These machines also need other techniques to fully monitor their operation.

A vibration analysis system usually consists of four basic parts:

1. Signal pickup(s), also called a transducer

2. A signal analyzer

3. Analysis software

4. A computer for data analysis and storage.

Vibration analysis can identify improper maintenance or repair practices. These can include improper bearing installation and replacement, inaccurate shaft alignment or imprecise rotor balancing. As almost $80 \%$ of common rotating equipment problems are related to misalignment and unbalance, vibration analysis is an important tool that can be used to reduce or eliminate recurring machine problems. Trending vibration levels can be used to compare similar machines from different manufacturers in order to determine if design benefits or flaws are reflected in increased or decreased performance. Ultimately, vibration analysis can be used as part of an overall program to significantly improve equipment reliability [10].

\section{B.2. Using vibration theory to machinery fault detection:}

At times when the induction motor has to be driven at speeds, wear and failure is imminent. When defects develop in these components, they give rise to higher vibration levels. With few exceptions, mechanical defects in a machine cause high vibration levels. Common defects that cause high vibrations levels in machines are:
(a) Unbalance of rotating parts
(b) Misalignment of couplings and bearings
(c) Bent shafts
(d) Worn or damaged gears and bearings
(e) Bad drive belts and chains
(f) Torque variations
(g) Electromagnetic forces

To generalize the above list, it can be stated that whenever either one or more parts are unbalanced, misaligned, loose, eccentric, out of tolerance dimensionally, damaged or reacting to some external force, higher vibration levels will occur.

The vibrations caused by the defects occur at specific vibration frequencies, which are characteristic of the components, their operation, assembly and wear. The vibration amplitudes at particular frequencies are indicative of the severity of the defects [10]. Vibration analysis aims to correlate the vibration response of the system with specific defects that occur in the machinery, its components, and trains or even in mechanical structure $[10,13]$.

\section{B.3. Ultrasound}

Most machines emit consistent sound patterns under normal operating conditions. These sound patterns (sonic signatures) can be defined and recognized, and therefore changes in these signatures can be seen as components begin to wear or deteriorate. In a certain sense, it is a different form of mechanical vibrations. Sound is a microscopic oscillation at the molecular level of a substance. Vibration is a macroscopic oscillation of structures - in other words, physical structures that move. Ultrasound is defined as sound waves that have frequency levels above $20 \mathrm{kHz}$, higher than the range of human hearing. Air-borne ultrasounds operate in the lower ultrasonic spectrum of 20-100 kHz and have the following properties: 
- Small objects easily block air-borne ultrasound.

- It does not penetrate solid surfaces (though it can go through cracks).

- Air-borne ultrasound radiates in a straight line. Ultrasound does not travel a great distance.

\section{B.4. Ultrasonic translator}

The ultrasonic translator (is generally a lightweight, hand-held device that can be easily carried within the plant and also into confined spaces.

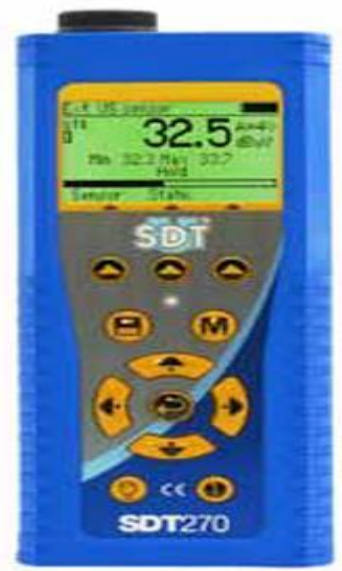

Fig. 7 the ultrasound translator

Air-borne ultrasound translators are relatively simple to use. They consist of a basic handheld unit with headphones, a meter, a sensitivity adjustment and (most often) interchangeable modules that are used in either a scanning mode or a contact mode. Some instruments have the ability to adjust the frequency response between 20 and 100 $\mathrm{kHz}$. An ultrasonic transmitter called a tone generator is often also included. The ultrasound can be 'heard' after it has been modified and processed into the audible range by a process called heterodyning. Heterodyning, as the word implies, is the mixing of two waves. The mixing of two waves produces the sum and the difference of the original waves, which also allow the shifting of a high-frequency sound to the audible range.

\section{B.5. Infrared thermography}

The thermographic camera sensor can be defined as an infrared detector whose roles are to absorb both the energy emitted by the object and the temperature of the surface to be measured and convert it into a signal. However, the energy actually detected by the infrared sensor depends on the emissivity coefficient of the surface to be measured.
The infrared thermographic camera can capture an image of the thermal pattern and can be used in several temperature ranges depending on the emissivity of the surface. The thermographic digital image captured by the camera is called a thermogram. Each pixel of it has a specific temperature value, and the contrast of the image is extracted from the differences in temperature of the object surface. It exists in many levels of grey. The color assignment for each degree of temperature is based on a group of colors with which it is allowed to view the object temperature. The infrared thermographic analysis has the advantage of offering a twodimensional signal, through its segmentation is capable of analyzing a specific hot spot or small zones Thermography is a useful predictive maintenance technique in the following ways:

- It does not make contact with the surface.

- The technique does not involve any hazardous actions.

- It can be used in hazardous zones.

- It is not affected by electromagnetic waves.

- Like other predictive techniques, it is used while systems are operating.

- It provides instant information.

- Data can be collected and stored in digital format.

However, thermography has some disadvantages, such as:

- The cost of the hardware can be quite high.

- Some systems have software limitations.

- The emissivity of the object must be calculated or should be known.

- The ambience should be homogenous with respect to the thermalenergy - any radiating source close to the area being monitored can affect the thermal scans.

- Distance, atmospheric conditions and temperature can affect the quality of images [12].

\section{B.6. Motor Current Signature Analysis (MCSA):}

Motor Current Signature Analysis (MCSA) is a technique used to determine the operating condition of AC induction motors without interrupting production. Motor current signature analysis is that it is sensing an electrical signal that contains current components. MCSA detect the faults at an early stage and avoid the damage and complete failure of the motor. By using MCSA, accurate analysis of fault is possible. Usually a decibel $(\mathrm{dB})$ versus frequency 
spectrum is used in order to give a wide dynamic range and to detect the exclusive current signature patterns that are characteristic of different faults. Motor Current Signature Analysis (MCSA) is based on current monitoring of induction motor therefore it is not very expensive. The MCSA uses the current spectrum of the machine for locating the fault frequencies. When a fault is present, the frequency spectrum of the line current becomes changed from healthy motor. Motor Current Signature Analysis (MCSA) based methods are used to diagnose the common faults of induction motor such as broken bar fault, short winding fault, bearing fault, and load fault. Current monitoring steps are sampler, pre-processor, Fault Detection Algorithm, Postprocessor.

There are several processing techniques to detect the faults

1) Fast Fourier Transform.

2) Shot Time Fourier Transform.

3) Wavelet Transform [14].

\section{Insulation Considerations:}

One successful way to predict motor failure is to test the strength of the insulation. The following sections describe four commonly used insulation tests.

\section{a- Insulation Resistance Test:}

An extremely useful test to determine the time of motor repair or replacement is the insulation resistance test. This test should be conducted at regular intervals as with any predictive test. "Trending" the data is the most useful way to obtain information from the investigation.

The technique used in the insulation resistance test is to attach a megohmmeter to a motor whose windings are at ambient temperature. The megohmmeter measures insulation resistance between the windings and the frame of the motor. A 500-volt megohmmeter should be used for motors with voltage ratings of 2,400 volts or less and a 1000-volt megohmmeter should be used if the rated voltage is over 2,400 volts. Once the readings are tabulated and charted, a pattern will develop to identify any trends in the data If the data remains constant time after time, the insulation system is in prime condition. When resistance drops after two or three successive tests, remove the motor from service. Conditions like high humidity may cause a motor's insulation resistance to fall so a low resistance on one test compared to the rest of the data set does not always mean troubling news.

\section{b- Polarization Index Test:}

The polarization index $(P-I)$ is a method used to determine if any substance has contaminated the motor enough to cause serious damage to the windings which would shorten the motor's life. In testing the P-I, usually a 500 volt megohmmeter provides a constant dc voltage between the motor's windings and frame for 10 minutes. The insulation resistance is measured after the first minute and after the tenth minute. A ratio is taken to compare the resistance at the tenth minute to the resistance at the first minute. As long as this ratio is greater than 2, the windings are operating properly. If the ratio is below 2, the Electrical Apparatus and Service Association (EASA) recommend having the motor's windings cleaned, baked, and retested. If the reading still falls below 2 , the motor may need to be rewound. The P-I test can be used for trending gradual deterioration in windings as well. Just like in the insulation resistance test, data can be logged at regular intervals and new tests can be compared to previous tests to observe any differences in the data.

\section{c- Surge Test:}

The insulation resistance test and $P$-I test are widely used in maintenance programs. These tests really only detect the final stages of an insulation wear-out so another means to determine the initial stages of deteriorating insulation was developed. This test is known as the surge test net examines the tum-tatum and phase-to-phase insulations. Phaseta-phase insulation is the protection found between the winding and ground while the tum-ta-tum insulation is a thin film applied to the surface of the copper wires. The surge test generates a voltage through the tum-tatum and phase-to-phase insulations by discharging a capacitor into a winding to rapidly pulse the voltage to a specified level. Viewing the pattern on an oscilloscope reveals the surge test findings through each phase of the motor. Since the three phases of the motor are identical, the test patterns must also be identical. Unequal patterns signal the tester that insulation short has occurred in the motor.

\section{d- DC High-Potential Test:}


Another test which better detects insulation weaknesses is the dc high-potential test. This test measures the insulation resistance compared to ground, but incorporates the dielectric strength of the insulation. This data is used to detect any weaknesses that could lead to a fault from voltage surges. The test applies a dc voltage in step increments up to an accepted voltage (usually twice the nameplate voltage plus $1,000 \mathrm{~V}$-according to IEEE Std.95) and measuring and plotting the leakage currents. The resultant plot of current versus voltage should be a straight line. An abrupt upswing in the plot indicates an insulation flaw and the test should be aborted immediately to avoid failure under tests.

\section{RESULTS AND DISCUSSIONS}

In this section, we are going to introduce MATLAB_SIMULINK model of a three phase squirrel cage induction motor. We are going to simulate multiple faults and analyze our results comparing the simulation of a healthy motor with that of a faulty one. The faults analyzed in this paper are: the broken bar, the bearing fault, unbalance voltage and phase, single phasing, and phase reversal

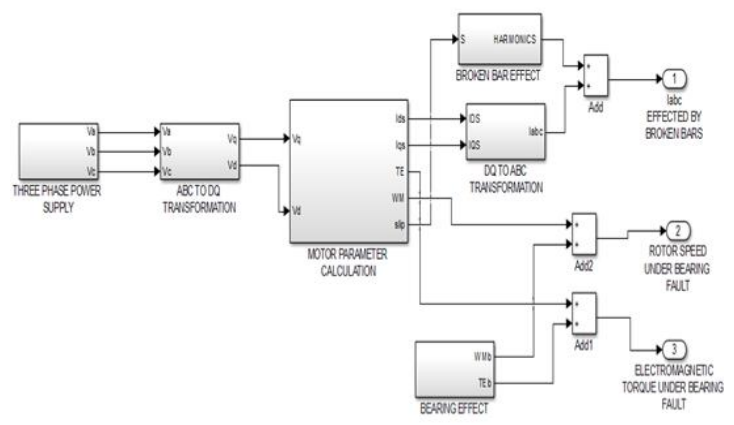

Fig. 8 Overall view of the three phase squirrel cage induction motor model

We will show the characteristics of the motor in the normal condition with no faults then , we will simulate the following faults of the induction motor : unbalance voltage and phase, single phasing, phase reversal, broken bar, and bearing fault. In each fault we will display the graphs of speed (in rpm), torque, and stator current. Then we will discuss the difference between the faulty motor and the normal one.

\section{A. Normal condition motor:}

The following are the graphs for the motor operating in the normal condition and its characteristics are as follows:

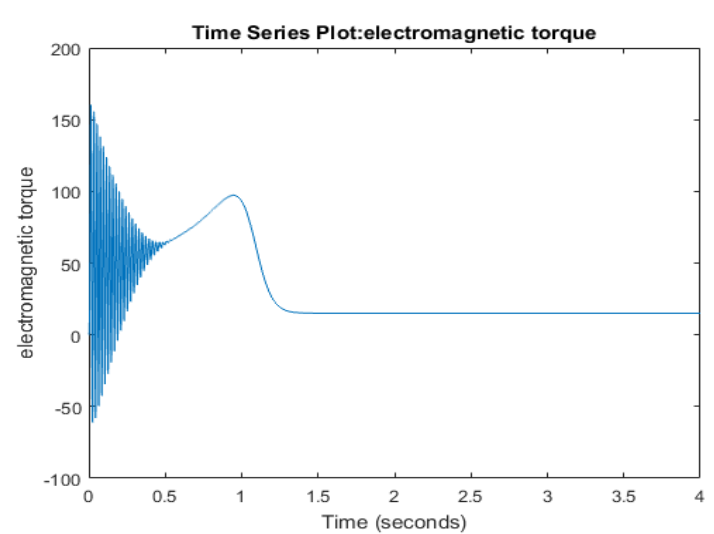

Fig. 9 the torque of the healthy motor

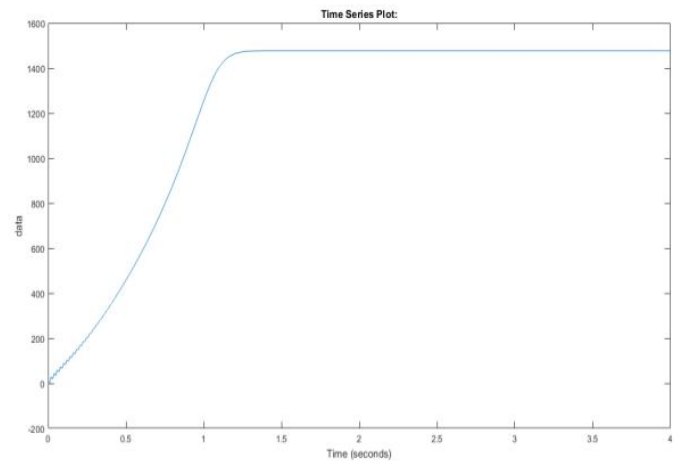

Fig. 10 the speed of the healthy motor



Fig. 11 the stator current of the healthy motor (same for all three phases)

\section{Characteristics:}

Speed: steady statespeed $=1476 \mathrm{rpm}$

- $\quad$ steady state time $1.34 \mathrm{~s}$

- $\quad$ Peak to peak ripple $=0$.

- Torque :

-Starting torque: $\mathrm{Ts}=157.7 \mathrm{~N} \cdot \mathrm{m}^{2}$

-Pulling up torque: $\mathrm{Tp}=96.52$ $N . m^{2}$ at $t=0.958 s$

-Steady state torque: $T_{\text {steady }}=$ 15.00 N.m2 at $t=1.604 \mathrm{~s}$ 
- Stator current:

$$
\begin{aligned}
& \text {-Phase a: Ip steady }=17.21 \mathrm{~A} \\
& \text {, } \quad \mathrm{Ip}_{\mathrm{rms}}=12.16 \mathrm{~A} \\
& \text {-Phase } \mathrm{b}: \quad \mathrm{p}_{\text {steady }}=17.21 \mathrm{~A} \\
& \text {, } \quad I p_{\text {rms }}=12.16 \mathrm{~A} \\
& \text {-Phase c: } \quad I p_{\text {steady }}=17.21 \mathrm{~A} \\
& \text {, } \quad \mathrm{Ip}_{\mathrm{rms}}=12.09 \mathrm{~A}
\end{aligned}
$$

\section{B. Faulty motors}

Now we will start the simulation of faults, first we will start with the electrical faults. Then, we will go to the mechanical ones.

\section{B.1. Unbalance voltage supply:}

\section{Unbalance phase:}

Unbalance phase fault is defined as the small variation of the phase angle which may occur because of the losses of the power supply or the bad connection of wires this fault is a dangerous one and it must detected earlier. In our simulation we introduced various cases of this fault and the results were as follows:

Case 1: unbalance angle $\phi=5^{\circ}$ and $\phi=8^{\circ}$ rad in phase $A$ :

\begin{tabular}{|c|c|c|c|c|c|}
\hline $\begin{array}{l}\text { Pha } \\
\text { se } \\
\text { of } \\
\text { the } \\
\text { sup } \\
\text { ply }\end{array}$ & $\begin{array}{l}\text { Pull up } \\
\text { torque } \\
T p_{a v}(N \\
. m)\end{array}$ & $\begin{array}{l}\text { Rippli } \\
\text { ng at } \\
\text { all- } \\
\text { time } \\
\Delta \text { tp }(N . \\
\text { m) }\end{array}$ & $\begin{array}{l}\text { Start } \\
\text { torque } \\
\mathrm{T}_{\text {start }}(\mathrm{N} \\
. \mathrm{m})\end{array}$ & $\begin{array}{l}\text { Steady } \\
\text { state } \\
\text { torque( } \\
\text { N.m) }\end{array}$ & $\begin{array}{l}\text { Ripplin } \\
\mathrm{g} \\
\Delta \mathrm{Tss}(\mathrm{N} \\
. \mathrm{m})\end{array}$ \\
\hline $\begin{array}{l}\phi= \\
0^{\circ}\end{array}$ & 96.52 & 0 & 157.7 & 15 & 0 \\
\hline $\begin{array}{l}\phi= \\
5^{\circ}\end{array}$ & 96.35 & 7.5 & 131.4 & 17.26 & 8.24 \\
\hline $\begin{array}{l}\phi= \\
8^{\circ}\end{array}$ & 95.965 & 10.43 & 158 & 14.95 & 20.51 \\
\hline
\end{tabular}

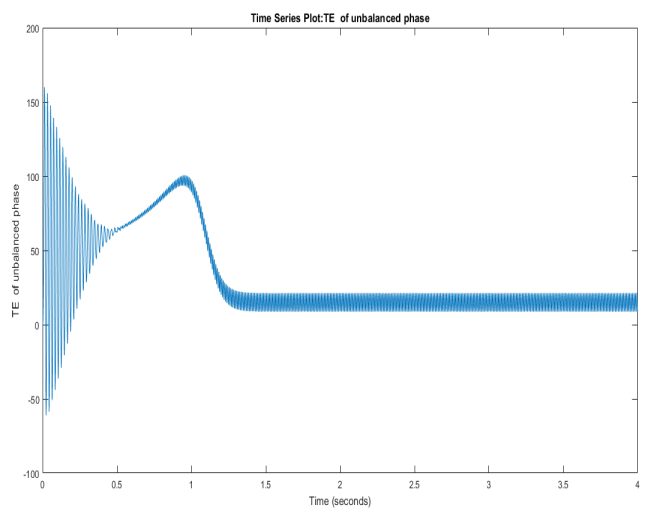

Fig. 12Torque vs.time plot of induction motor in unbalace phase case 1

\section{a-Torque:}

Table 2 the torque for unbalance phase fault

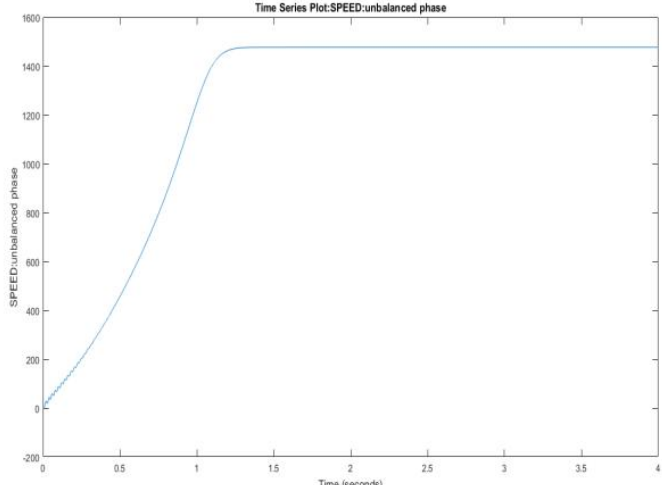

\begin{tabular}{|c|c|c|c|}
\hline $\begin{array}{l}\text { Phase of } \\
\text { the } \\
\text { supply }\end{array}$ & $\begin{array}{l}\text { Peak too } \\
\text { peak } \\
\text { ripple(rpm) }\end{array}$ & $\begin{array}{l}\text { Max } \\
\text { peak(rpm) }\end{array}$ & $\begin{array}{l}\text { Min } \\
\text { peak(rpm) }\end{array}$ \\
\hline$\phi=0^{\circ}$ & 0 & 1476 & 1467 \\
\hline$\phi=5^{\circ}$ & 0.15 & 1477.3 & 1476.8 \\
\hline$\phi=8^{\circ}$ & 00 & 1477.4 & 1477.02 \\
\hline
\end{tabular}

Fig. 13 Speed vs. time plot of induction motor in b-Speed: unbalance phase case $1\left(\phi=5^{\circ}\right)$

Table 3 the speed of the motor in case of unbalance phase case 1

\section{c-Stator current:}

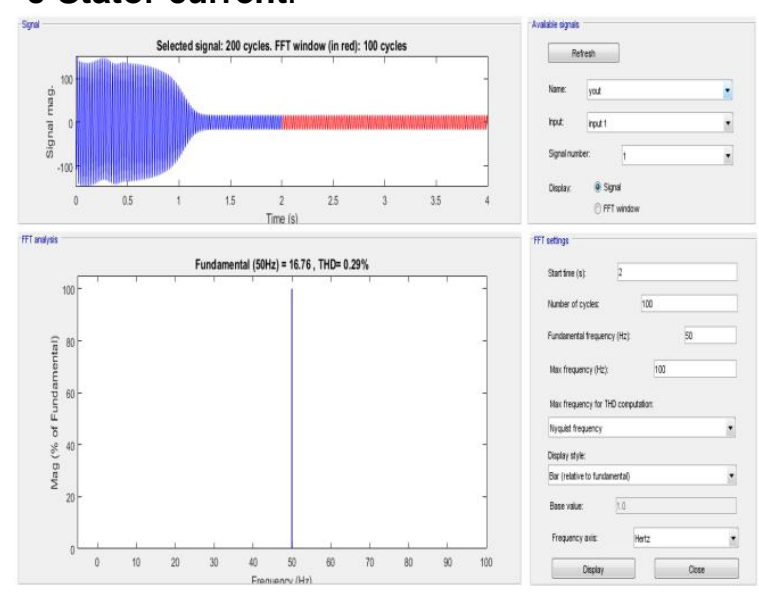

Fig. 14-a- unbalance phase stator current in phase $A\left(5^{\circ}\right.$ phase)

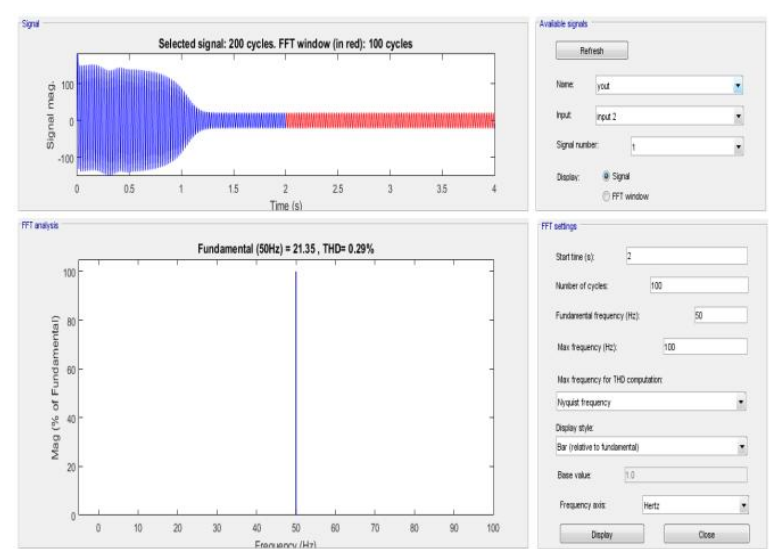

Fig.14-b. unbalance phase stator current of phase $B\left(5^{\circ}\right.$ phase $)$ 


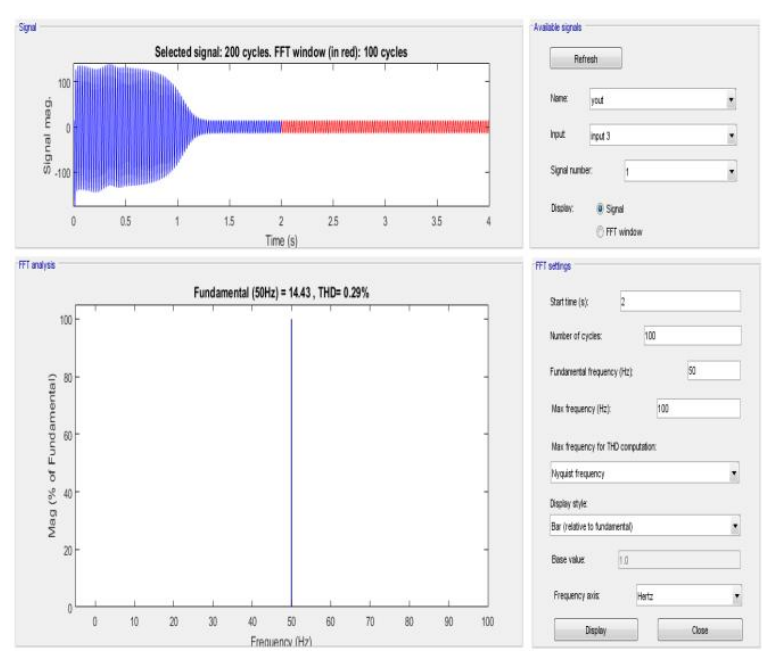

Fig. 14-c- unbalance phase stator current in phase $\mathrm{C}\left(5^{\circ}\right.$ phase $)$

Table 4 the stator current of the induction motor in case of unbalance phase case 1

\begin{tabular}{|c|c|c|c|}
\hline $\begin{array}{c}\text { Phase of } \\
\text { the supply }\end{array}$ & $\begin{array}{c}\text { Phase } \\
\text { Alas peak }(A)\end{array}$ & $\begin{array}{c}\text { Phase B, } \\
\operatorname{lbs}_{\text {peak }}(A)\end{array}$ & $\begin{array}{c}\text { Phase C, } \\
\operatorname{Ics}_{\text {peak }}(A)\end{array}$ \\
\hline $\begin{array}{c}\boldsymbol{\phi}=\mathbf{0}^{\circ} \\
\text { (healthy) }\end{array}$ & 17.21 & 17.21 & 17.21 \\
\hline $\boldsymbol{\phi}=\mathbf{5}^{\circ}$ & 16.69 & 21.18 & 14.45 \\
\hline $\boldsymbol{\phi}=\mathbf{8}^{\circ}$ & 16.93 & 23.84 & 13.04 \\
\hline
\end{tabular}

$>$ Case 2: unbalance angle $\phi=5^{\circ}$ and $\phi=8^{\circ}$ rad in phase $B$ :

Speed:

Table 5 speed of the induction motor in case of unbalance phase (case 2)

\begin{tabular}{|l|l|l|l|}
\hline $\begin{array}{l}\text { Phase } \\
\text { of the } \\
\text { supply }\end{array}$ & $\begin{array}{l}\text { Peak too } \\
\text { peak } \\
\text { ripple(rpm) }\end{array}$ & $\begin{array}{l}\text { Max } \\
\text { peak(rpm) }\end{array}$ & $\begin{array}{l}\text { Min } \\
\text { peak(rpm) }\end{array}$ \\
\hline $\boldsymbol{\phi = \mathbf { 0 } ^ { \circ }}$ & 0 & 1476 & 1467 \\
\hline $\boldsymbol{\phi = \mathbf { 5 } ^ { \circ }}$ & 0.15 & 1477.3 & 1476.8 \\
\hline $\boldsymbol{\phi = \mathbf { 8 } ^ { \circ }}$ & 00 & 1477.4 & 1477.02 \\
\hline
\end{tabular}

Table 6 the torque of the induction motor in case

\begin{tabular}{|c|c|c|c|c|c|}
\hline $\begin{array}{l}\text { Phase } \\
\text { of the } \\
\text { supply }\end{array}$ & $\begin{array}{l}\text { Pull } \\
\text { up } \\
\text { torque } \\
\text { Tp pav } \\
\text { (N.m) }\end{array}$ & $\begin{array}{l}\text { Rippling } \\
\text { at all } \\
\text { time } \Delta \text { tp } \\
\text { (N.m) }\end{array}$ & $\begin{array}{l}\text { Start } \\
\text { torque } \\
\mathrm{T}_{\text {start }} \\
\text { (N.m) }\end{array}$ & $\begin{array}{l}\text { Steady } \\
\text { state } \\
\text { torque } \\
\text { (N.m) }\end{array}$ & $\begin{array}{l}\text { Rippling } \\
\Delta \mathrm{Tss} \\
\text { (N.m) }\end{array}$ \\
\hline$\phi=0^{\circ}$ & 96.52 & 0 & 157.7 & 15 & 0 \\
\hline$\phi=5^{\circ}$ & 96.54 & 7.11 & 156.7 & 14.88 & 12.46 \\
\hline$\phi=8^{\circ}$ & 96.16 & 10.9 & 158.6 & 15.176 & 20.48 \\
\hline
\end{tabular}

Table 7 stator currents torque of the induction motor in case of unbalance phase (case 2)

\begin{tabular}{|l|l|l|l|}
\hline $\begin{array}{l}\text { Phase of } \\
\text { the supply }\end{array}$ & $\begin{array}{l}\text { Phase } \\
\text { Alas }{ }_{\text {peak }}(\mathrm{A})\end{array}$ & $\begin{array}{l}\text { Phase B, } \\
\operatorname{lbs}_{\text {peak }}(\mathrm{A})\end{array}$ & $\begin{array}{l}\text { Phase C, } \\
\operatorname{lcs}_{\text {peak }}(\mathrm{A})\end{array}$ \\
\hline $\boldsymbol{\mathbf { } = \mathbf { 5 } ^ { \circ }}$ & 13.26 & 20.28 & 18.83 \\
\hline $\boldsymbol{\Phi = \mathbf { 8 } ^ { \circ }}$ & 10.72 & 22.64 & 20.27 \\
\hline
\end{tabular}

Case 3: unbalance angle $\phi=5^{\circ}$ and $\phi=8^{\circ} \mathrm{rad}$ in phase $\mathrm{C}$ :

a-Speed and electromagnetic torque: after varying the phase angle in phase $\mathrm{C}$ to $5^{\circ}$ and $8^{\circ}$ we observed that the speed and the electromagnetic torque are the same as case 1 and case 2 (see tables 5 and $6)$.

\section{b-Stator current:}

Table 8 stator currents torque of the induction motor in case of unbalance phase (case 3)

\begin{tabular}{|l|l|l|l|}
\hline $\begin{array}{l}\text { Phase of } \\
\text { the supply }\end{array}$ & $\begin{array}{l}\text { Phase } \\
\text { Alas }_{\text {peak }}(\mathrm{A})\end{array}$ & $\begin{array}{l}\text { Phase B, } \\
\operatorname{lbs}_{\text {peak }}(\mathrm{A})\end{array}$ & $\begin{array}{l}\text { Phase C, } \\
\operatorname{Ics}_{\text {peak }}(\mathrm{A})\end{array}$ \\
\hline $\boldsymbol{\phi = \mathbf { 5 } ^ { \circ }}$ & 20.52 & 18.77 & 13.22 \\
\hline $\boldsymbol{\phi}=\mathbf{8}^{\circ}$ & 23.3 & 20.38 & 10.85 \\
\hline
\end{tabular}

Case 4: unbalance angle $\phi=5^{\circ}$ on phase $A$ and $\phi=5^{\circ}$ in phase $C$ :

\section{a- Speed and electromagnetic Torque:}

After varying the phase angle in phase $C$ to $5^{\circ}$ and $8^{\circ}$ we observed that the speed and the electromagnetic torque are the same as case 1 and case 2 (see tables 3.4 and 3.5)

Table 9 Speed of the induction motor in case of unbalance phase (case 4)

\begin{tabular}{|c|c|c|c|c|c|}
\hline $\begin{array}{l}\text { Pha } \\
\text { se } \\
\text { of } \\
\text { the } \\
\text { sup } \\
\text { ply }\end{array}$ & $\begin{array}{l}\text { Pull } \\
\text { up } \\
\text { torque } \\
\mathrm{Tp}_{\mathrm{av}}(\mathrm{N} \\
. \mathrm{m})\end{array}$ & $\begin{array}{l}\text { Rippling } \\
\text { at all- } \\
\text { time } \Delta \operatorname{tp}( \\
\text { N.m) }\end{array}$ & $\begin{array}{l}\text { Start } \\
\text { torque } \\
\mathrm{T}_{\text {start }}(\mathrm{N} \\
. \mathrm{m})\end{array}$ & $\begin{array}{l}\text { Steady } \\
\text { state } \\
\text { torque( } \\
\text { N.m) }\end{array}$ & $\begin{array}{l}\text { Ripplin } \\
\mathrm{g} \\
\Delta \mathrm{Tss}( \\
\text { N.m) }\end{array}$ \\
\hline $\begin{array}{l}\phi= \\
0^{\circ}\end{array}$ & 96.52 & 0 & 157.7 & 15 & 0 \\
\hline $\begin{array}{l}\phi= \\
5^{\circ}\end{array}$ & 96.54 & 7.11 & 156.7 & 15.22 & 20.30 \\
\hline
\end{tabular}

b-Stator current:

Table 10 Stator currents of the induction motor in case of unbalance phase (case 4)

\begin{tabular}{|l|l|l|l|}
\hline $\begin{array}{l}\text { Phase of } \\
\text { the supply }\end{array}$ & $\begin{array}{l}\text { Phase } \\
\text { Alas }\end{array}$ & $\begin{array}{l}\text { Phase } \\
\operatorname{lbs}_{\text {peak }}(A)\end{array}$ & $\begin{array}{l}\text { Phase C, } \\
\operatorname{Ics}_{\text {peak }}(A)\end{array}$ \\
\hline $\boldsymbol{\Phi = \mathbf { 5 } ^ { \circ }}$ & 20.78 & 23.21 & 10.017 \\
\hline
\end{tabular}

We can deduce that the phase unbalance increases the stator current on a phase and decrease it on the others.

Increasing the phase angle causes the increase of the current on two phases and the decrease of current of the remaining phase.

- Adding phase angle $\phi$ on phase $A: I_{a}$ and $I_{c}$ decrease, while $I_{b}$ increases.

- Adding phase angle $\phi$ on phase $b: I_{b}$ and $I_{c}$ increase while $I_{a}$ decreases. 
- Adding phase angle $\phi$ on phase $A: I_{a}$ increases, $I_{b}$ remains unchanged, and $I_{c}$ decrease.

- Adding phase angle $\phi$ on phase A and phase $\mathrm{C}$ : $\mathrm{I}_{\mathrm{a}}$ increases, $\mathrm{I}_{\mathrm{b}}$ increases, $I_{c}$ decreases.

- Adding phase angle $\phi$ on phase $A$ and phase $b: I_{a}$ decreases, $I_{b}$ increases, $I_{c}$ decreases.

- Adding phase angle $\phi$ on phase $b$ and phase $\mathrm{C}$ : $\mathrm{I}_{\mathrm{a}}$ decreases, $\mathrm{I}_{\mathrm{b}}$ increases, $I_{c}$ decreases.

\section{Unbalanced voltage}

The supplied three phase voltage significantly affects their operating performance. When the supplied three phase voltage is unbalanced, the startup transients , dynamic performance and steady state characteristics of the motor will vary accordingly .In our simulation we tried many cases and the results are shown in figures (9 to 14) and tables (11 to 16).

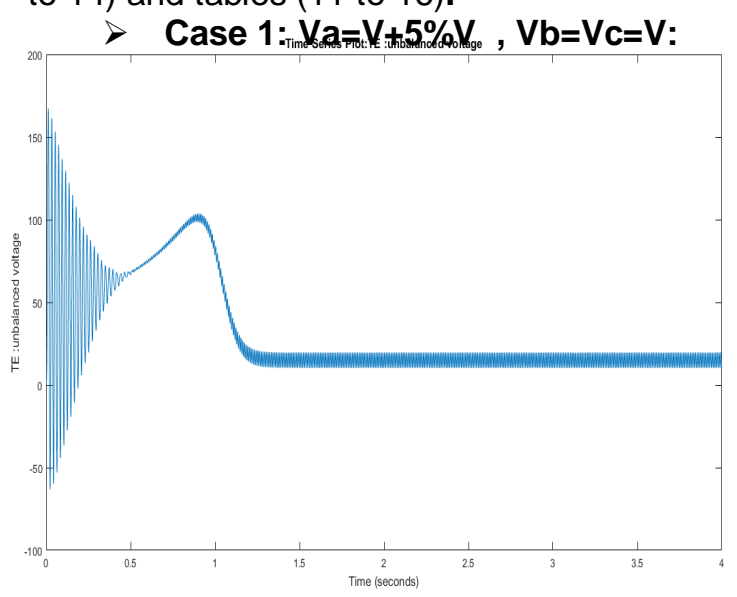

Fig. 15 torque of the induction motor with unbalance voltage case 1

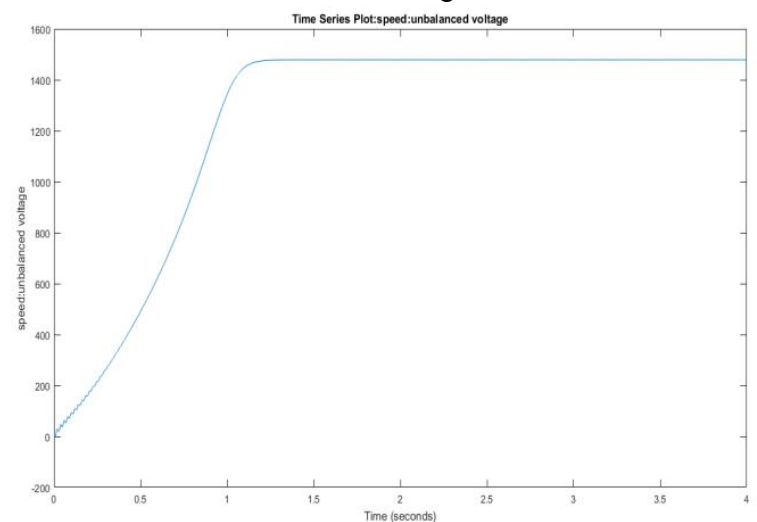

Fig. 16 the torque-speed of the induction motor with unbalance voltage case 1

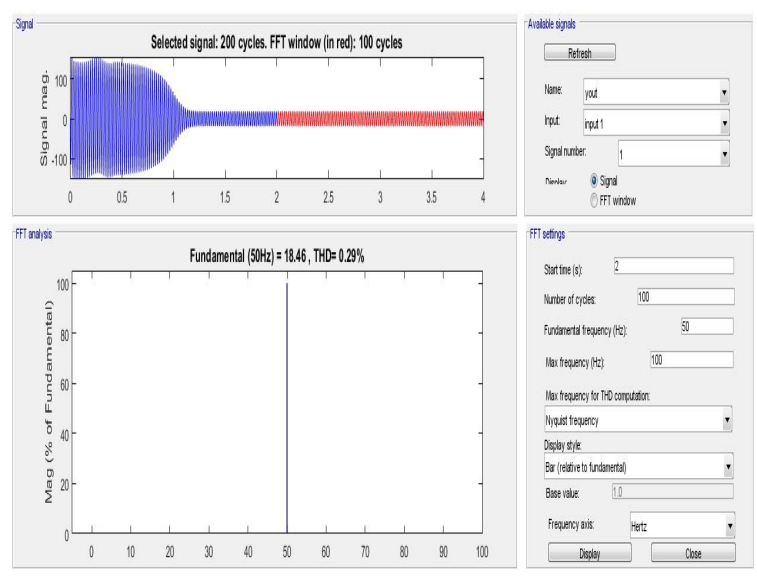

Fig.17-a the stator current of the induction motor with unbalance voltage case 1 in phase $A$



Fig.17-b the stator current of the induction motor with unbalance voltage case 1 in phase $B$

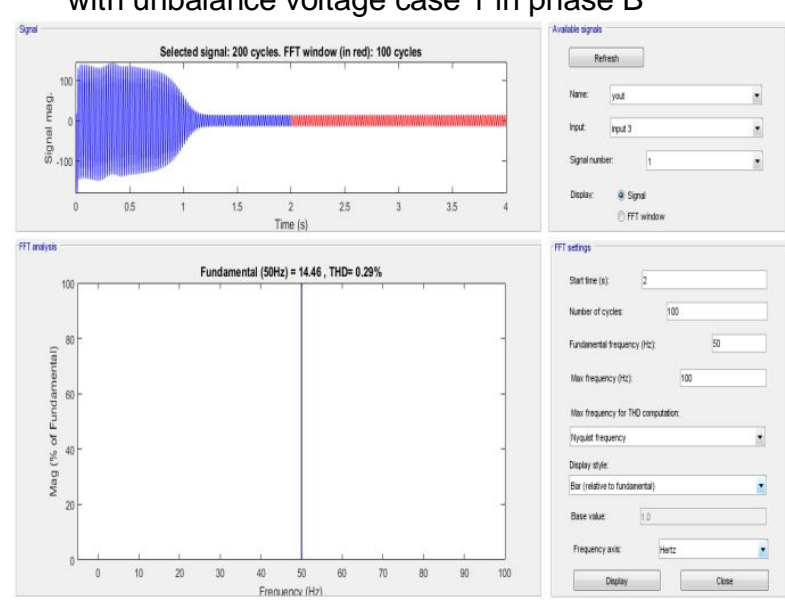

Fig.17-c the stator current of the induction motor with unbalance voltage case 1 in phase $C$

a-Speed: steady state speed $=1478$

rpm

b-Torque: 
Table11 the torque for the induction motor with unbalance voltage fault (case 1)

\begin{tabular}{|c|c|c|c|c|}
\hline $\begin{array}{c}\text { Pull up } \\
\text { torque } \\
\begin{array}{c}\mathrm{T} p_{\text {av }}(\mathrm{N} . \\
\mathrm{m})\end{array}\end{array}$ & $\begin{array}{c}\text { Rippling at } \\
\text { all- } \\
\text { time } \Delta \mathrm{tp}(\mathrm{N} . \\
\mathrm{m})\end{array}$ & $\begin{array}{c}\text { Start } \\
\text { torque } \\
\mathrm{T}_{\text {start }}(\mathrm{N} . \\
\mathrm{m})\end{array}$ & $\begin{array}{c}\text { Steady } \\
\text { state } \\
\text { torque(N. } \\
\mathrm{m})\end{array}$ & $\begin{array}{c}\text { Rippling } \\
\Delta \mathrm{Tss}(\mathrm{N} . \\
\mathrm{m})\end{array}$ \\
\hline $\begin{array}{c}101.9 \\
\text { to }\end{array}$ & $\mathbf{4 . 1 6}$ & $\mathbf{1 6 5}$ & 18.7 & 11.44 \\
97.74 & & & & \\
\hline
\end{tabular}

c -Stator current:

Table 12 the stator current of the motor with unbalance voltage fault (case 1)

\begin{tabular}{|c|c|c|}
\hline $\begin{array}{l}\text { Phase } \\
\operatorname{las}_{\text {peak }}(A)\end{array}$ & $\begin{array}{l}\text { Phase } \\
\operatorname{lbs}_{\text {peak }}(A)\end{array}$ & $\begin{array}{l}\text { Phase } \\
\operatorname{lcs}_{\text {peak }}(A)\end{array}$ \\
\hline 15.01 & 18.11 & 19.22 \\
\hline
\end{tabular}

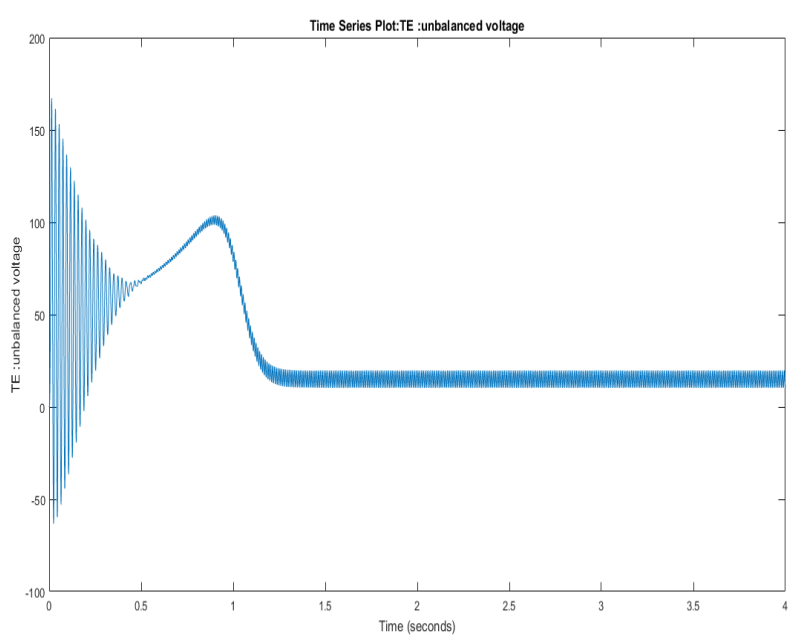

Fig. 18 Torque vs. time plot for the induction motor with unbalance voltage fault (case 2)

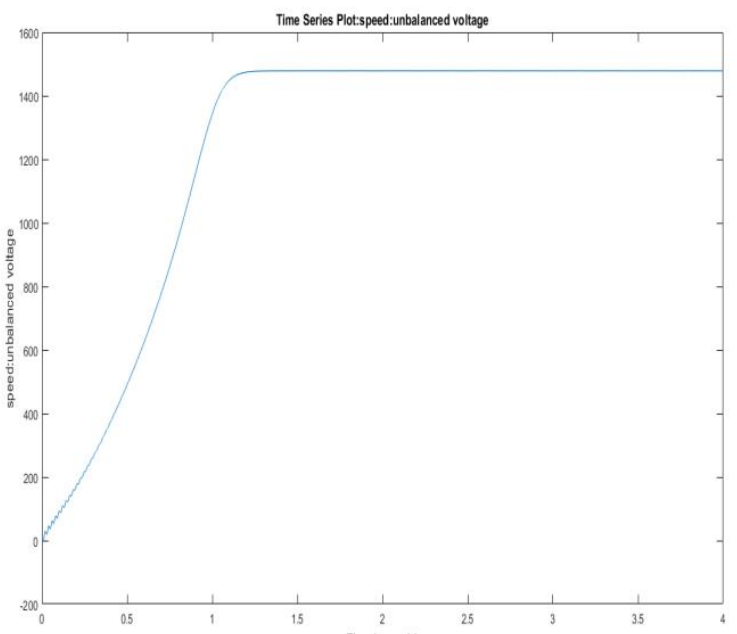

Fig. 19 Speed vs. time plot for the induction motor with unbalance voltage fault (case 2)

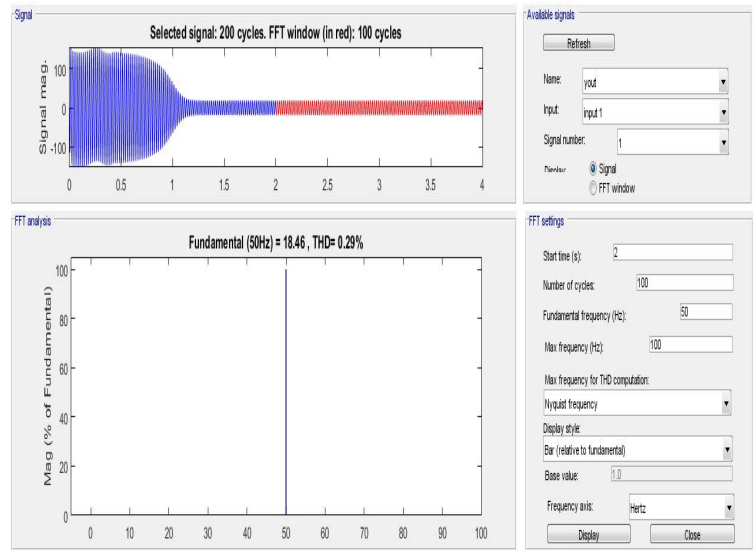

Fig. 20-a the stator current of the motor with unbalance voltage - phase $\mathrm{A}$ (case 2)

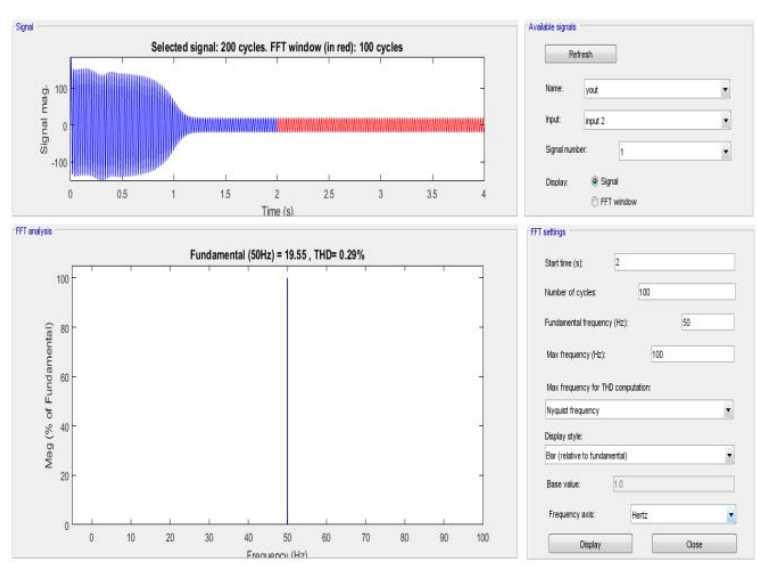

Fig. 20-b the stator current of the motor with unbalance voltage -phase B (case 2)

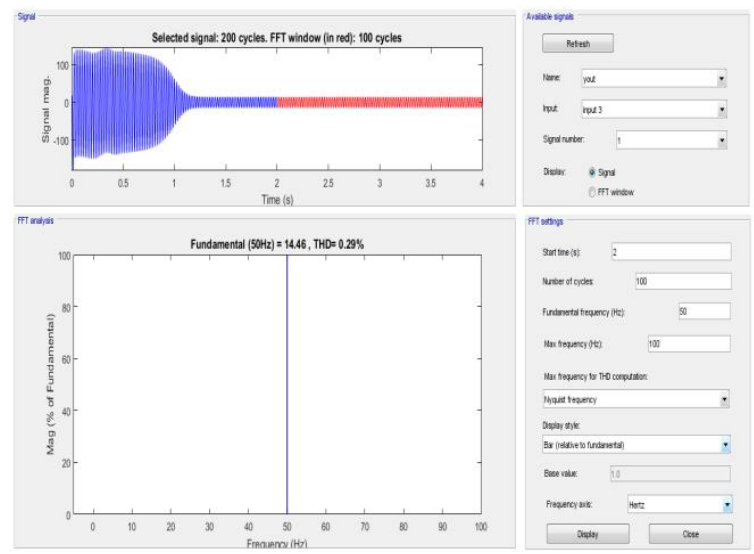

Fig. 20-c the stator current of the motor with unbalance voltage -phaseC (case 2)

Speed and electromagnetic torque: after varying the voltage in phase $A$ by $5 \%$ (while keeping $\mathrm{Vb}$ and $\mathrm{Vc}$ as they are), we observed that the speed and the electromagnetic torque are the same as in case 1 (see table 11) 


\section{b-Stator current:}

Table 13 the stator currents of the motor with unbalance voltage fault (case 2)

\begin{tabular}{|l|l|l|}
\hline $\begin{array}{l}\text { Phase A } \\
\operatorname{las}_{\text {peak }}(A)\end{array}$ & $\begin{array}{l}\text { Phase B, } \\
\operatorname{lbs}_{\text {peak }}(A)\end{array}$ & $\begin{array}{l}\text { Phase C, } \\
\operatorname{Ics}_{\text {peak }}(A)\end{array}$ \\
\hline 18.4 & 19.22 & 14.99 \\
\hline
\end{tabular}

\section{Case $3: \mathrm{Vc}=\mathrm{V}+5 \% \mathrm{~V}, \mathrm{Va}=\mathrm{Vb}=\mathrm{V}$ :}

Speed and Torque: after varying the voltage in phase $\mathrm{C}$ by $5 \%$ (while keeping $\mathrm{Va}$ and $\mathrm{Vc}$ as they are) we observed that the speed and the electromagnetic torque are the same as in case 1 (see table 11).

\section{b-Stator current:}

Table 14 the stator currents of the motor with unbalance voltage fault (case 3)

\begin{tabular}{|l|l|l|l|}
\hline $\begin{array}{l}\text { Phase } \\
\operatorname{las}_{\text {peak }}(A)\end{array}$ & $\begin{array}{l}\text { Phase } \\
\operatorname{lbs}_{\text {peak }}(A)\end{array}$ & $\begin{array}{l}\text { Phase } \\
\operatorname{Ics}_{\text {peak }}(A)\end{array}$ & $C$, \\
\hline 19.01 & 15.08 & 18.03 & \\
\hline
\end{tabular}

When the magnitude of the voltage of the supply is changed the current at the phases increases and decreases by the same amount, we can also remark that it does not reach $20 \mathrm{~A}$ as in phase unbalance. In magnitude unbalance, there are one or two loaded phases (larger current)

\section{Case 4: $\mathrm{Va}=\mathrm{Vc}=\mathrm{V}+5 \% \mathrm{~V}, \mathrm{Vb}=\mathrm{V}$ :}

Speed and electromagnetic torque: after varying the voltage in phase $A$ and $C$ by $5 \%$ (while keeping $\mathrm{Vb}$ the same) we observed that the speed and the electromagnetic torque are the same as in case 1 (see table 11)

. Table 15 the stator currents of the motor with unbalance voltage fault (case 4)

\begin{tabular}{|c|c|c|}
\hline $\begin{array}{ll}\text { Phase } & \text { A } \\
\operatorname{las}_{\text {peak }}(A) & \end{array}$ & $\begin{array}{l}\text { Phase } \\
\operatorname{lbs}_{\text {peak }}(A)\end{array}$ & $\begin{array}{l}\text { Phase } \\
\operatorname{lcs}_{\text {peak }}(A)\end{array}$ \\
\hline 16.88 & 15.84 & 19.83 \\
\hline
\end{tabular}

\section{Case 5: $\mathrm{Va}=\mathrm{Vb}=\mathrm{V}+5 \% \mathrm{~V}, \mathrm{Vc}=\mathrm{V}$ :}

Speed and electromagnetic Torque: after varying the voltage in phase $A$ and $B$ by $5 \%$ (while keeping $V_{c}$ the same) we observed that the speed and the electromagnetic torque are the same as in case 1 (see table 11).

Table 16 the stator currents of the motor with unbalance voltage fault (case 5)

\begin{tabular}{|l|l|l|l|}
\hline $\begin{array}{l}\text { Phase } \\
\operatorname{las}_{\text {peak }}(\mathrm{A})\end{array}$ & $\mathrm{A}$ & $\begin{array}{l}\text { Phase } \\
\operatorname{lbs}_{\text {peak }}(\mathrm{A})\end{array}$ & $\begin{array}{l}\text { Phase } \\
\operatorname{Ics}_{\text {peak }}(\mathrm{A})\end{array}$ \\
\hline 15.98 & 19.93 & $\mathrm{C}$, \\
\hline
\end{tabular}

\section{B.2. Phase reversal fault:}

The phase reversal occurs when two of the three phases of the supply line reverse. Most of the motors will react very badly to such situation. Motor suddenly rotates in the wrong direction causing major collateral damage. The results of the torque-speed, and stator current (phase A) are shown in figures (21, 22 and 23 , respectively).

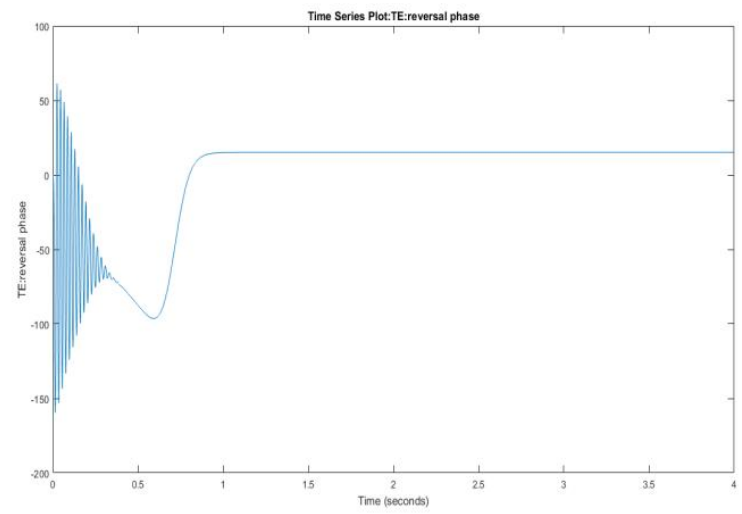

Fig. 21 torque vs. time plot for the motor with phase reversal fault

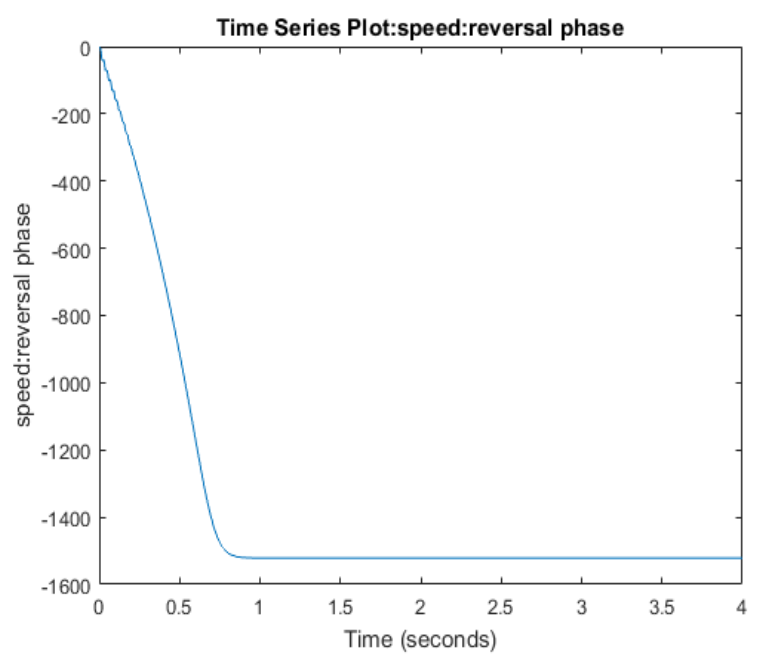

Fig. 22 speed vs. time plot for the motor with phase reversal fault

Speed: $-1521 \mathrm{rpm}$ with reverse direction (a very dangerous fault).

Torque: Starting torque $=60.95$ and -158.8

N.m. (a large ripple)

Pull down torque: $\mathrm{Tp}=-95.58 \mathrm{~N} \cdot \mathrm{m}$

Current: $\mathrm{la}=\mathrm{lb}=\mathrm{lc}=17.47$.

We remark that all phase currents increased by the same amount. 


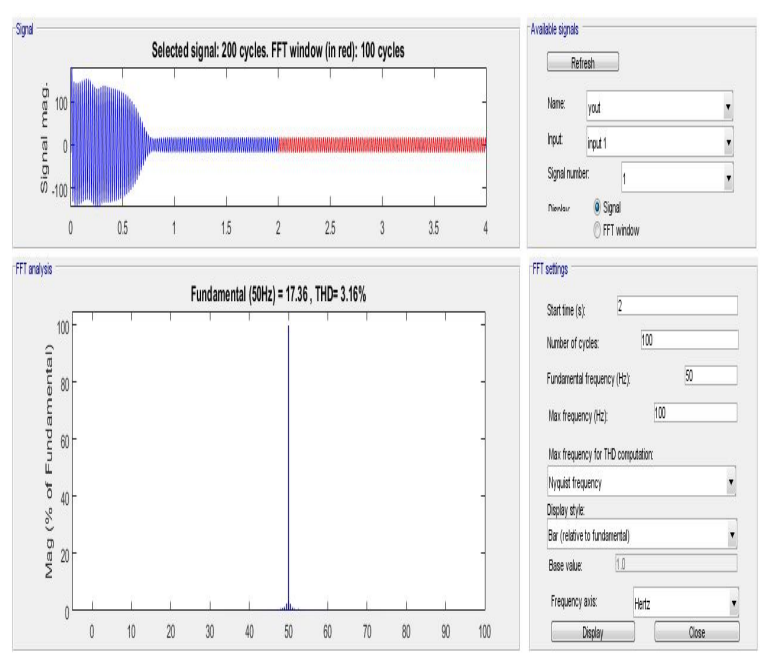

Fig. 23 stator current (in phase A) for the motor with phase reversal fault

\section{B.3. Single phasing fault: Phases} disconnecting the currents are: $\mathrm{la}=66.79 \mathrm{~A}$, $\mathrm{lb}=55.02 \mathrm{~A}, \mathrm{lc}=31.59 \mathrm{~A}$,in single phasing is dangerous so we must check the supply before feeding it to the motor.

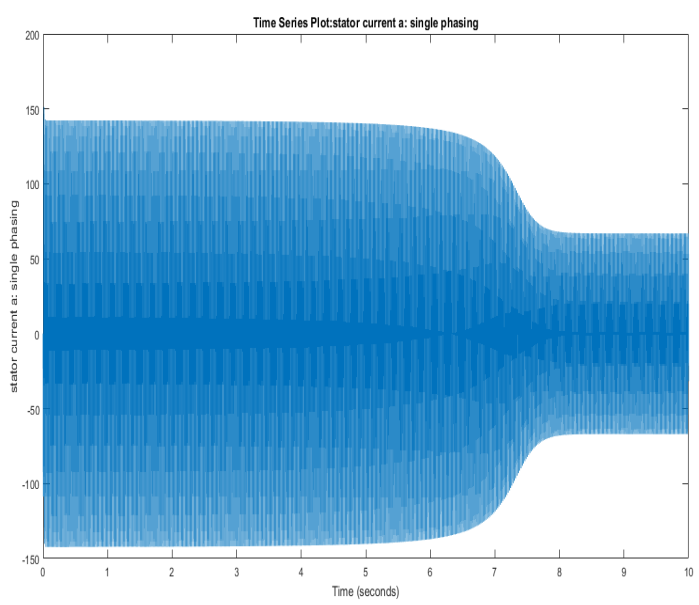

Fig.24-a stator current $A$ of the motor for single phasing fault

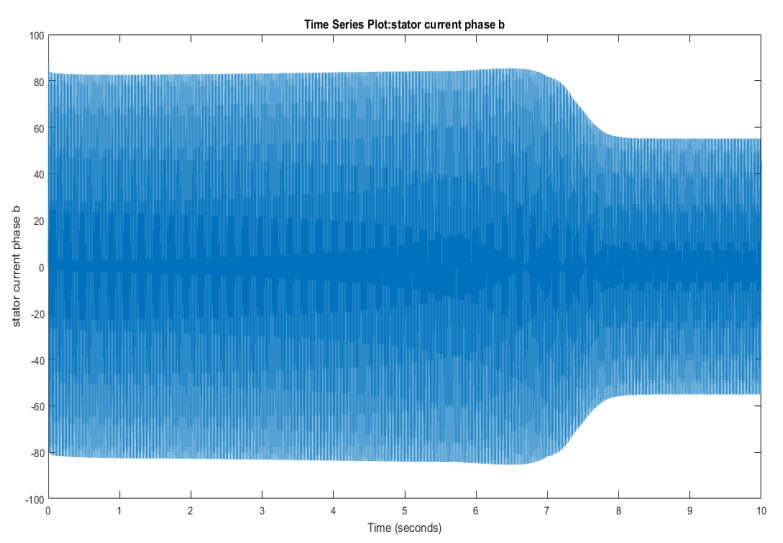

Fig. 24-b stator current b of the motor for single phasing fault

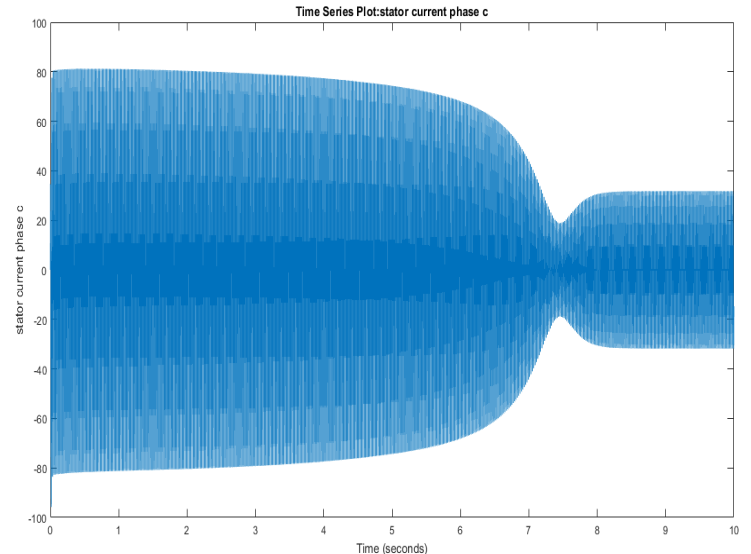

Fig. 24-c stator current Cof the motor for single phasing fault

\section{Comparison between multiple power supply faults:}

Unbalance of phase: we can see from the simulation that in almost all the experiments that we performed the current $\mathrm{lb}$ increases with respect to the others (the increase and decrease in current are observed in la, Ic according to which case we are studying).

Unbalance voltage: almost the same effect of phase unbalance fault in effecting the speed and the electromagnetic torque with small rippling in the steady state, here the currents are converged to each other like (19.01A, $15.08 \mathrm{~A}, 18.03 \mathrm{~A}$ ) also note that the values do not exceed the value of $20 \mathrm{~A}$, but we have two rising currents which is not the case in phase unbalance.

Single phasing fault: it is different from unbalanced voltage supply, if it occurs ,it is characterized by very high current in the phases reaches $(66.79,55.02,31.59)$ with low speed to the other electrical faults(around $1436 \mathrm{rpm}$ ). We can also see that peak to peak ripple is higher.

Phase reversal: it is more obvious to detect, it forces the motor to run in counter clockwise direction with low starting torque.

\section{Broken bar fault:}

The broken rotor bars of the SCIM which were modeled using MATLAB-SIMULINK based on the frequency spectrum of the stator current it is used for the teaching of the rotor faults of the induction motor.

Since the load torque is very low we cannot detect the harmonics so we must fix the load to 15 N.m. So we use MCSA method with inversing procedure where we used some experimental values. Scientist made a lot of 
predictions concerning this fault so we choose only one which is : $f_{\text {brb }}=(1-2 K S) f_{0}$ where : $f 0$ is the fundamental frequency of ,K is integer number , $S$ is the slip, $f_{\text {brb }}$ : the frequency of the harmonic so we make an injection of that harmonic , the first harmonic has amplitude as follows:

$$
I b r b=\frac{I s \cdot N b}{N} \quad(9)
$$

withNb as the number of broken bars, $\mathrm{N}$ is the total number of bars, and Is is the amplitude of the fundamental frequency 50 $H Z$. Now we add a feed back to the system, we notice the following:

-at la: has $(1 \pm 2 S) f_{\mathrm{s}}$ and $(1 \pm 4 S) f_{\mathrm{s}}$ harmonics (it means two broken bars )

-at Ib: no harmonic

-at Ic: we inject a harmonic at frequency

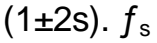

- The effect of the broken bar fault on the stator current (in phase A) and on the torque is shown in figures (25) and (26) respectively:

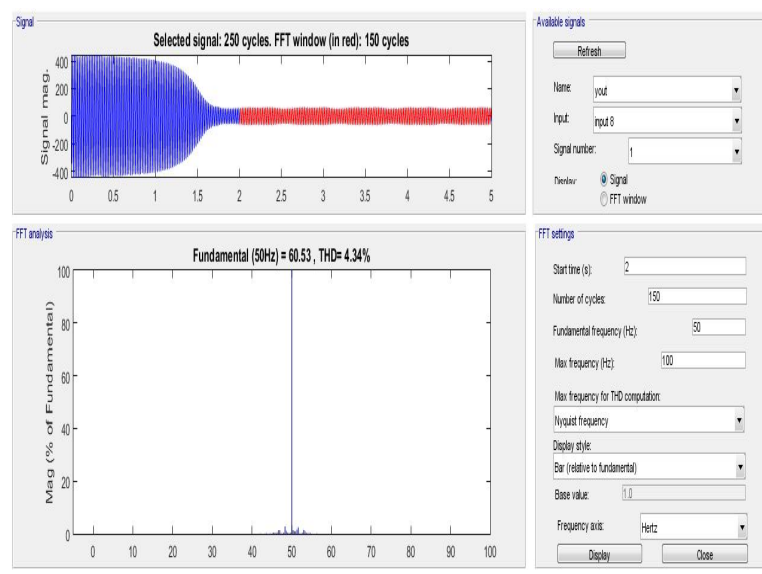

Fig. 25-a Stator current A for the motor with the broken bar fault

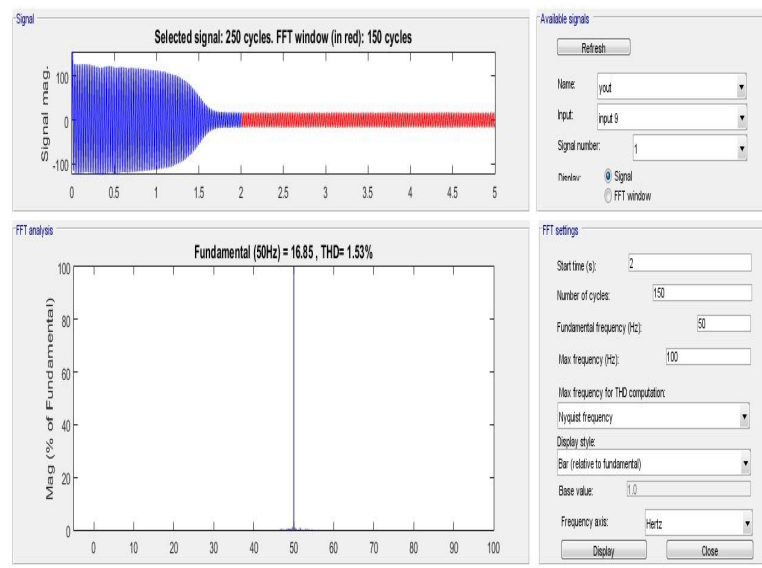

Fig. 25-b Stator current B for the motor with the broken bar fault

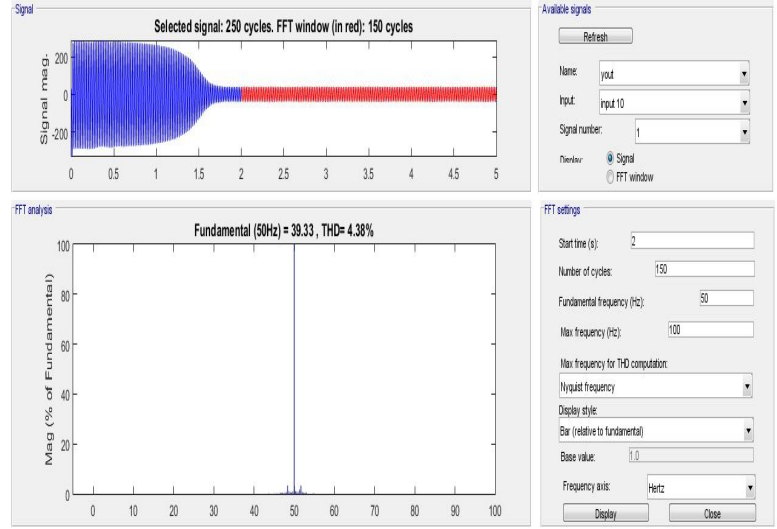

Fig. 25-c Stator current C for the motor with the broken bar fault

Torque:

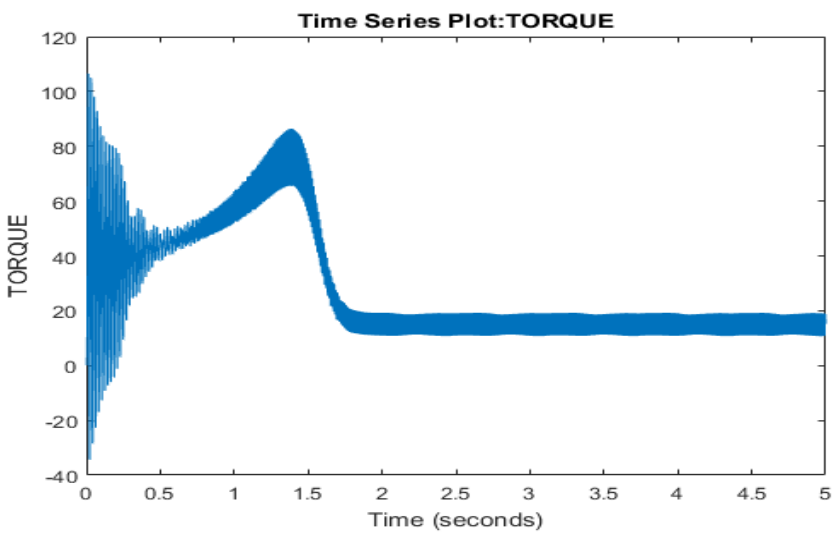

Fig. 26 torque vs. time for the motor with broken bar fault

Torque: We notice that harmonics do not appear with low load $\mathrm{Tm}=0$

Table 17 the torque results of the motor under the

\begin{tabular}{|c|c|c|}
\hline $\begin{array}{c}\text { Starting } \\
\text { torque Tstart } \\
\text { (N.m) }\end{array}$ & $\begin{array}{c}\text { Pull up } \\
\text { torque Tpu } \\
\text { (N.m) }\end{array}$ & $\begin{array}{c}\text { Rippling } \\
\text { steady state } \\
\text { torque (N.m) }\end{array}$ \\
\hline $\mathbf{1 2 4 . 1}$ & $\mathbf{7 9 . 4 1}$ & $\mathbf{1 0 . 9 1}$ \\
\hline \multicolumn{3}{|c|}{} \\
\hline
\end{tabular}

The stator current: It will increase $\mathrm{I}_{\mathrm{asp}}=56.54 \mathrm{~A}$ with harmonics at $(1 \pm 2 \mathrm{~S}) \mathrm{f0}$ and

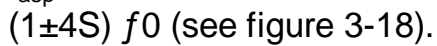

\section{E. Bearing fault:}

As stated previously, the bearing is the weakest component of an induction motor. It is the largest cause of fault in induction motor, so detecting it is a necessity .and one of the ways of detecting bearing faults is observing the change of the motor characteristics due to the change of friction constant. However, the problem here is that it is hard to distinguish between bearing fault 
and the other faults since they have the same effect as that of some other faults( like the overload fault ). Another problem is that it is hard to see the bearing fault in the time domain .so we use the MCSA method for detecting bearing faults. In this method, we are going to show the oscillation in the steady state torque, and the frequencies of machine vibrations depending on which bearing surface contains the fault, one of the most common bearing fault is the out race fault which appears on the stator current with frequency of:

$$
f_{0}=\frac{N_{b}}{2} \times f_{r}\left(1-\frac{D_{b}}{D_{c}} \cos \beta\right)
$$

And these harmonics can be translated into torque and speed variation as follows

$$
\begin{aligned}
& T=T_{0}+T c \cdot \cos \left(\Phi_{0} t\right) \\
& \omega_{r}(t)=\left(-T c / J \omega_{s}\right) \cdot \sin \left(\Phi_{0} t\right)+\omega_{m} \\
& T_{c}=\frac{K t \cdot T l o a d}{\sqrt{k T^{2}+\omega 0^{2} J^{2}}} \approx T_{\text {load }}
\end{aligned}
$$

Where $\omega_{0}$ : the angular frequency harmonic under bearing fault

$\omega_{\mathrm{m}}$ : the nominal rotor speed

$\mathrm{T}_{0}$ : the nominal electromagnetic torque

$\mathrm{T}_{\mathrm{c}}$ : the amplitude of the torque under the bearing effect

\section{Effect of Friction constant, K:}

$>$ Case 1 : K=0.1 N.m.s



Fig. 27 Torque vs. Time plot under bearing fault (case 1)

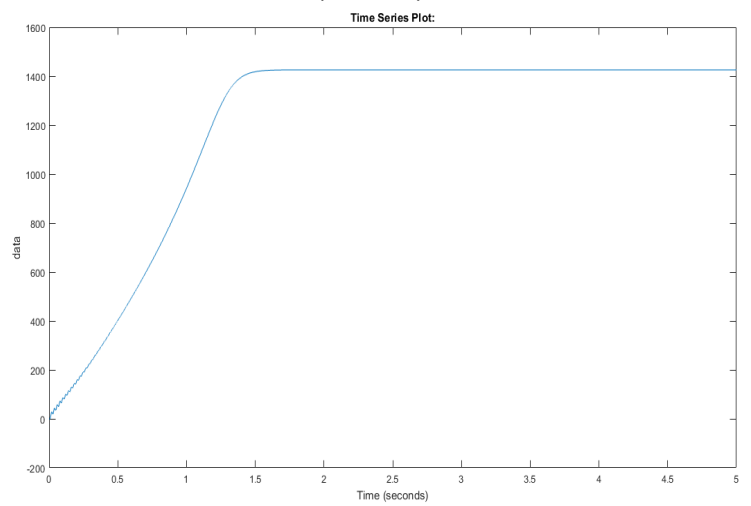

Fig. 28 speed vs. time under bearingfault( case 1)

\section{$>\quad$ Case 2 :Friction constant $\mathrm{K}=0.2$}

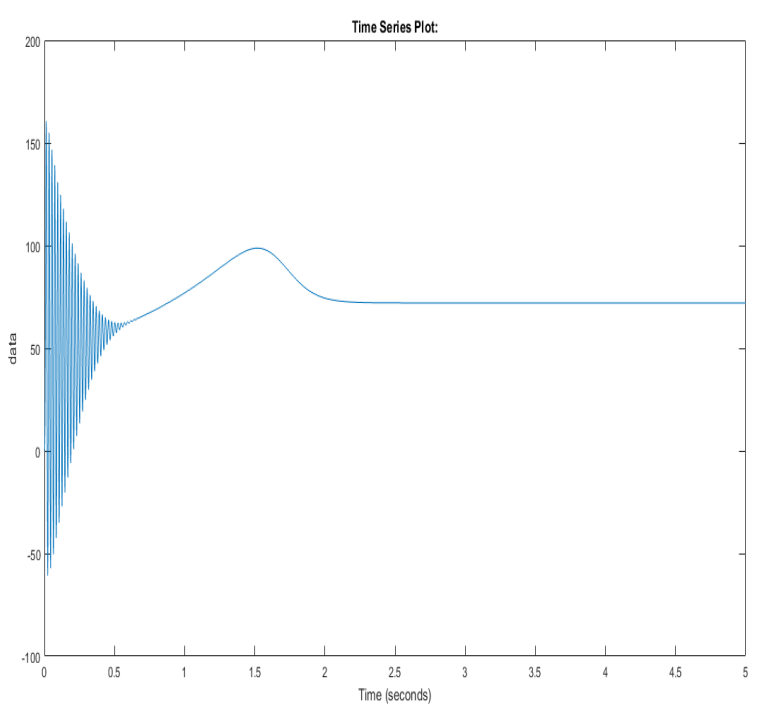

Fig. 29 torque under bearing fault (case 2)



Fig. 30 Speed under bearing fault (case 2)

The procedure is as follows:

Table 18 results of the torque and speed due to variation of $\mathrm{K}$

\begin{tabular}{|c|c|c|}
\hline $\begin{array}{c}\text { Constant of } \\
\text { friction K }\end{array}$ & $\begin{array}{c}\text { Steady state } \\
\text { torque in N.m }\end{array}$ & Speed in rpm \\
\hline 0 & $\begin{array}{c}\text { Same as in } \\
\text { the healthy } \\
\text { model }\end{array}$ & $\begin{array}{c}\text { Same as in } \\
\text { the healthy } \\
\text { model }\end{array}$ \\
\hline 0.1 & 44.86 & 1426 \\
\hline 0.2 & 72.13 & 1362 \\
\hline
\end{tabular}

We remark that as $\mathrm{K}$ increases the steady state torque increases and the speed decreases as shown in table 18. 


\section{Bearing fault diagnosis using MCSA method}

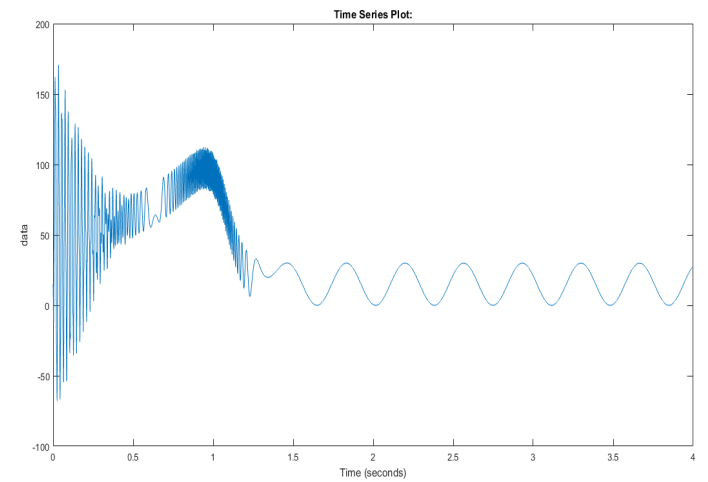

Fig. 31 Torque under bearing fault

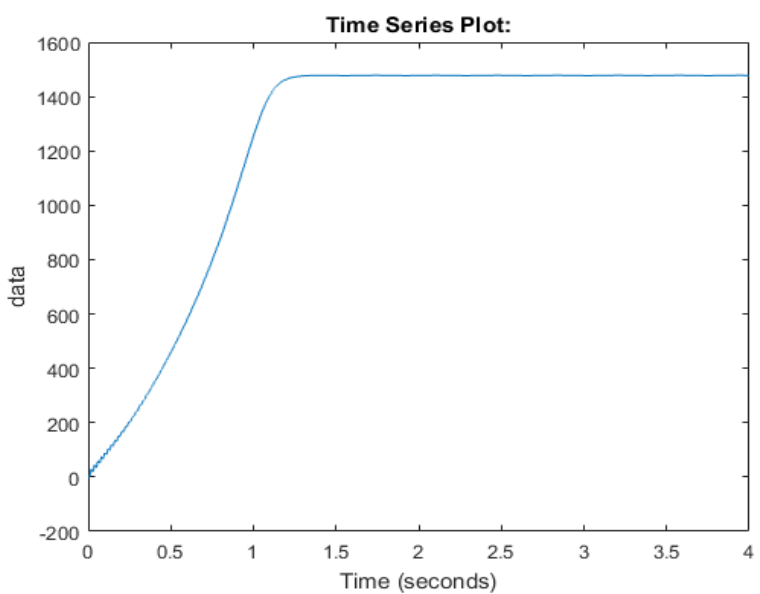

Fig. 32 speed under bearing fault

We observe that by using the MCSA method the rippling torque appears clearly (the vibration of the rotor) compared to the variation of the friction constant method.

\section{CONCLUSION}

The goal of any motor maintenance program is to reduce unplanned downtime which is costly for any manufacturer. There are other benefits to incorporating a maintenance program like the ones described in this report. Preventative tasks can improve motor efficiency which will result in improved plant efficiency. At the end of this project we were able to introduce the concept of the predictive maintenance using our MATLAB SIMULINK software. We were able to show the effect of motor faults both electrical and mechanical on the characteristics of the motor (stator current, torque and speed) where we spotted the variance of the characteristics with respect to the healthy ones.

\section{Acknowledgments}

This work is part of the research activities within the Laboratory of Signals and Systems, university of Boumerdes, Algeria. Special thanks to Professor Hamid BENTARZI, the director of the signals and systems Laboratory at the University of Boumerdes-Algeria for his valuable advice and continual support.

\section{REFERENCES}

[1] M. H. Benbouzid. . A Review of Induction Motors Signature Analysis as a Medium for Faults Detection, IEEE Transactions on Industrial Electronics, Vol.47, No.5, (October 2000), pp. 984-993, ISSN 0278-0046.

[2] A. H. Bonnett and G.C. Soukup, "Cause and Analysis of Stator and Rotor Failures in ThreePhase Squirrel-Cage Induction Motors", IEEE Transactions on Industrial Electronics, Vol.28, No.4, (July/August 1992), pp. 921-937, ISSN 0278-0046.

[3] P. J. Tavner, L. Ran., J. Penman and H. Sedding . Condition Monitoring of Rotating Electrical Machines, The Institution of Engineering and Technology - IET, $2^{\text {nd }}$ Edition, 1987. ISBN 978-0863417412, London, UK.

[4] S. Soergel and P. Rastgoufard, "An Analysis of Induction Motor Predictive Maintenance Techniques", Proceedings of 28th Southeastern Symposium on System Theory, 31 March-2 April 1996, Baton Rouge, LA, USA, USA, DOI: $10.1109 /$ SSST.1996.493518

[5] Abdelghani CHAHMI, "Diagnosis of the Induction Machine Using Advanced Signal Processing Methods ", Algerian Journal of Signals and Systems, Vol.3, Issue 3, September 2018. pp:143-150.

[6] Erik Leandro Bonaldi et. Al., "Predictive Maintenance by Electrical Signature Analysis to Induction Motors", book chapter, INTECH OPEN. DOI: http://dx.doi.org/10.5772/48045.

[7] Steven J. Chapman. "Electrical machinery fundamentals" .BAE systems Australia.2004

[8] George Mcpherson. "An introduction to electrical machines and transformers ". 1981

[9] Fitzgerald, Kingsley \& Electric Machinery (6th Edition, 2003) ;

[10] PareshGirdhar "Practical Machinery Vibration Analysis and Predictive Maintenance ".2004

[11] Mansour Ojaghi1, Mahdi Sabouri. "Dynamic Modelling and Simulation of Induction Motors with Different Bearing Faults".2013

[12] Timothy J.Barnish, Dr.MichaelR.Muller, and Donald J. Kasten." Motor maintenance: a survey of techniques and results".

[13] Mohammed Omar." Non-destructiveTesting Methods and New Applications" .2012.

[14] Chaitali S. Kalaskar, Vitthal J. Gond "Motor Current Signature Analysis to Detect the Fault in Induction Motor" 2014. 